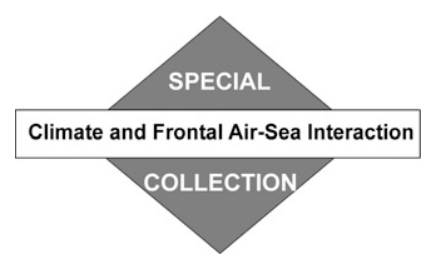

\title{
Mechanisms for the Maintenance of the Wintertime Basin-Scale Atmospheric Response to Decadal SST Variability in the North Pacific Subarctic Frontal Zone
}

\author{
SATORU OKAJIMA, ${ }^{\mathrm{a}}$ HisASHI NAKAMURA,,${ }^{\mathrm{a}, \mathrm{b}}$ KAZUAKI NiSHII, ${ }^{\mathrm{c}}$ TAKAFUMI MiYASAKA, ${ }^{\mathrm{a}}$

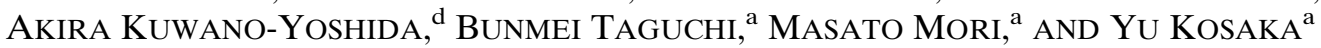 \\ ${ }^{a}$ Research Center for Advanced Science and Technology, The University of Tokyo, Tokyo, Japan \\ ${ }^{\mathrm{b}}$ Application Laboratory, JAMSTEC, Yokohama, Japan \\ ${ }^{\mathrm{c}}$ Graduate School of Bioresources, Mie University, Tsu, Japan \\ ${ }^{\mathrm{d}}$ Disaster Prevention Research Institute, Kyoto University, Shirahama, Japan
}

(Manuscript received 28 March 2017, in final form 4 October 2017)

\begin{abstract}
Mechanisms for the maintenance of a large-scale wintertime atmospheric response to warm sea surface temperature (SST) anomalies associated with decadal-scale poleward displacement of the North Pacific subarctic frontal zone (SAFZ) are investigated through the following two ensemble experiments with an atmospheric general circulation model (AGCM): one with climatological-mean SST and the other with positive SST anomalies along the SAFZ prescribed on top of the climatological-mean SST. As actually observed, the simulated January ensemble response over the North Pacific is anticyclonic throughout the depth of the troposphere, although its amplitude is smaller. This response is maintained through energy conversion from the ensemble climatological-mean circulation realized under the climatological SST as well as feedback from anomalous transient eddy activity, suggesting that the response may have characteristics as a preferred mode of variability (or "dynamical mode"). Conversions of both available potential energy and kinetic energy from the climatological-mean state are important for the observed anomaly, while the latter is less pronounced for the model response. Net transient feedback forcing is also important for both the observed anomaly and simulated response. These results imply that a moderate-resolution $\left(\sim 1^{\circ}\right)$ AGCM may be able to simulate a basin-scale atmospheric response to the SAFZ SST anomaly through synoptic- and basin-scale dynamical processes. Weaker PNA-like internal variability in the model may lead to the weaker response, suggesting that misrepresentation of intrinsic atmospheric variability can affect the model response to the SST anomaly.
\end{abstract}

\section{Introduction}

Owing to greater persistence of SST anomalies than atmospheric anomalies, a robust atmospheric response to oceanic forcing, if any, could contribute to improvement in seasonal forecast skill. Influence of extratropical SST anomalies on the large-scale atmospheric circulation has long been believed to be insignificant, in the presence of a prevailing remote influence from the tropics (Lau 1997; Alexander et al. 2002) and large intrinsic atmospheric variability (Frankignoul 1985; Kushnir et al. 2002). Over decades, a number of studies have strived to assess atmospheric responses to prescribed midlatitude SST anomalies by using various atmospheric general circulation models (AGCMs) with

Corresponding author: Satoru Okajima,okajima@atmos.rcast. u-tokyo.ac.jp
SST anomalies imposed over different regions (e.g., Lau and Nath 1990; Kushnir and Lau 1992; Peng et al. 1995, 1997; Lau 1997). Peng et al. (1997) and Peng and Whitaker (1999) suggested that a large-scale AGCM response to the prescribed SST anomaly is sensitive to its relative position to the background westerlies simulated in the AGCM, as confirmed by Kushnir et al. (2002). In fact, Robinson (2000) reported difficulties in AGCM experiments in obtaining systematic atmospheric responses to positive and negative SST anomalies prescribed in the midlatitudes.

To assess the importance of midlatitude SST variability in forcing wintertime basin-scale atmospheric anomalies, recent studies have been focusing on persistent SST anomalies in the North Pacific subarctic frontal zone (SAFZ), taking advantage of satellite measurements, newer models, and longer observational data. The North Pacific SAFZ forms a boundary between the 
warm Kuroshio and cool Oyashio waters (Yasuda 2003; Kida et al. 2015) with a climatologically sharp meridional SST gradient and vigorous atmosphere-ocean interaction (Kwon et al. 2010; Kelly et al. 2010; Nakamura et al. 2015). The sharp meridional SST gradient across the SAFZ was unresolved in AGCMs used in the aforementioned studies, because of their rather coarse horizontal resolution. Tanimoto et al. (2003) and Taguchi et al. $(2009,2012)$ have found that, unlike in most of the North Pacific basin where surface heat flux anomalies due to changes in near-surface wind, air temperature, and humidity force SST anomalies, warm (cold) SST anomalies along the SAFZ tend to enhance (reduce) heat release into the atmosphere, which can be regarded as thermodynamic forcing by the SAFZ variability on the overlying atmosphere. In fact, using linear inverse modeling, Smirnov et al. (2014) suggested that a substantial fraction $(\sim 50 \%)$ of the wintertime monthly SST variability is intrinsic to the ocean over the North Pacific western boundary current region, while much of the variability in other regions arises from atmospheric forcing on the ocean. It is thus worth investigating the persistent large-scale atmospheric response to the SAFZ SST variability.

Meridional displacement of the SAFZ, which is due to incoming oceanic Rossby waves, yields meridionally confined persistent SST anomalies (Seager et al. 2001; Schneider et al. 2002; Nonaka et al. 2006; Taguchi et al. 2007; Newman et al. 2016). Indeed, decadal SST variability in winter exhibits a primary maximum off the east coast of Japan along the SAFZ and a secondary maximum over the subtropical frontal zone (Nakamura and Kazmin 2003). The SST variability in SAFZ exhibits no significant simultaneous correlation with the tropical SST variability, suggesting that the former variability is inherent to the North Pacific (Taguchi et al. 2012), while the SST over the subtropical frontal zone varies in seesaw with the tropical SST (Nakamura et al. 1997).

Nakamura et al. (1997) have shown that wintertime decadal SST anomalies in the SAFZ tend to accompany persistent anomalies in the surface Aleutian low and upper-level anomalies that closely resemble the PacificNorth American (PNA) pattern (Wallace and Gutzler 1981). Since then, the relationship between SST anomalies associated with oceanic fronts and large-scale atmospheric anomalies has been investigated. Focusing on the Kuroshio Extension, Joyce et al. (2009) suggested from atmospheric reanalysis data that the surface stormtrack axis shifts meridionally following a decadal displacement of the SAFZ. O'Reilly and Czaja (2015) also pointed out that when the Kuroshio Extension is less meandering, atmospheric heat transport by transient eddies increases over the western North Pacific.
Frankignoul et al. (2011) found that persistent dipolelike atmospheric anomalies, which are uncorrelated with SST variability in the tropics, tend to emerge in association with a meridional shift of the Oyashio front. Kwon and Joyce (2013) also revealed that the northward shift of the SAFZ leads to the suppression of the stormtrack activity in the North Pacific. Analyzing observational data and a long-term coupled ocean-atmosphere general circulation model (CGCM) integration, Taguchi et al. (2012) revealed that late-autumn warming around the SAFZ due to its northward shift forces the persistent weakening of the Aleutian low, which peaks in January and decays rapidly through February. As suggested by Newman et al. (2016), the aforementioned covariability between SST anomalies in the SAFZ and large-scale atmospheric anomalies may constitute a feedback loop to contribute to the so-called Pacific decadal variability.

Those findings are based on observational data analysis and a coupled model experiment. Anomalies in a coupled system are a mixture of the atmospheric forcing pattern onto a given SST anomaly and a response to it, and the anomalies can therefore be influenced by forcings other than the SAFZ SST anomalies as well as atmospheric internal variability. While an exact match between the observed anomalies and AGCM response is therefore not expected, AGCM experiments can extract a response to the SAFZ SST anomalies, which would substantiate the aforementioned findings on oceanic forcing to the large-scale atmospheric circulation.

In a recent study, Smirnov et al. (2015) compared large-scale atmospheric responses obtained in a pair of experiments with different horizontal resolutions of a state-of-the-art AGCM. In their higher-resolution $\left(0.25^{\circ} \times 0.25^{\circ}\right)$ experiment, a robust basin-scale anticyclonic response is simulated throughout the depth of the troposphere to a warm SST anomaly prescribed only within the SAFZ, while such a deep response disappears in their lower-resolution $\left(1.0^{\circ} \times 1.0^{\circ}\right)$ experiment, which simulates a lower-tropospheric cyclonic response only. They stressed the importance of mesoscale atmospheric perturbations in forcing the high-resolution (and thus more realistic) response. However, the aforementioned work by Taguchi et al. (2012) presented deep anticyclonic anomalies in association with the northward shift of the SAFZ in a long-term integration of a CGCM with a modest atmospheric resolution of $1.0^{\circ} \times 1.0^{\circ}$, motivating the reexamination of the atmospheric response to the SAFZ variability with a modest resolution $\left(\sim 1^{\circ}\right)$ AGCM. In fact, an AGCM ensemble experiment by Okajima et al. (2014) successfully reproduced a persistent basin-scale anticyclonic anomaly observed in October 2011 as a robust response to an extreme warm 
(a) DJF SST stddev

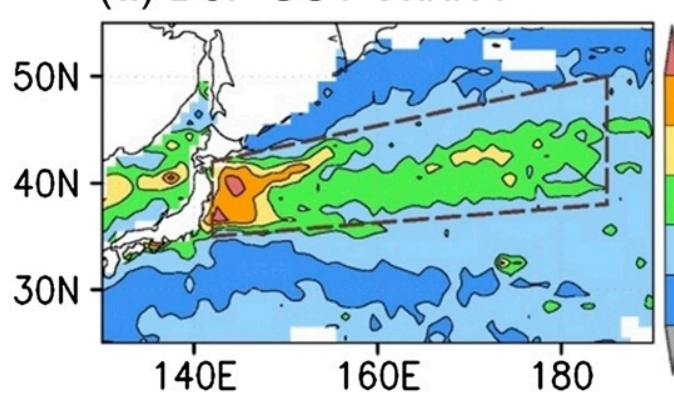

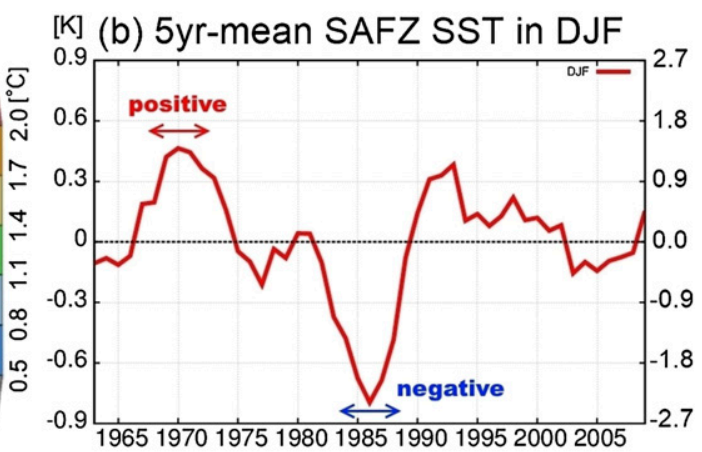

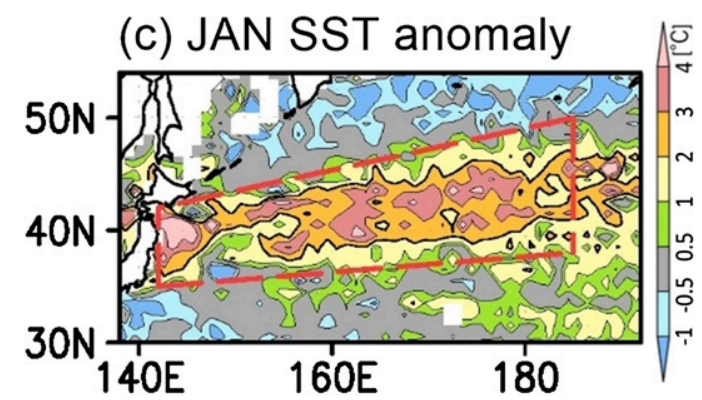

FIG. 1. (a) Standard deviation of DJF-mean SST $\left({ }^{\circ} \mathrm{C}\right.$; color) for the period $1960-2006$, based on quality-controlled $1^{\circ} \times 1^{\circ}$ gridded ICOADS data prepared by Y. Tanimoto. Grid boxes for which data are missing over more than half of the period are not colored. The brown trapezoid marks the SAFZ region. (b) Time series of the 5-yr movingaveraged DJF-mean SST anomaly $\left({ }^{\circ} \mathrm{C}\right)$ within the trapezoid region in (a). Labels on the left ordinate are for the observed anomaly, and those on the right ordinate correspond to the multiplied anomaly prescribed in the model as the model boundary condition. Positive and negative phases of the decadal variability are indicated with arrows. (c) January SST anomaly $\left({ }^{\circ} \mathrm{C}\right.$; color) extracted as half of the difference between the positive and negative phases of decadal variability of the SAFZ and then multiplied by 3 . The red trapezoid marks the SAFZ region, as in (a), in which the positive SST anomaly is prescribed as the boundary condition for the POS experiment.

SST anomaly in the SAFZ. These two studies with the horizontal resolution of the atmospheric model being about $1.0^{\circ}$ suggest that synoptic and basin-scale processes, in addition to mesoscale processes, can be of particular importance for maintaining the basin-scale response, a hypothesis that is tested by the present study.

This paper is organized as follows. Section 2 describes the data and experimental design. Section 3 compares observed anomalies and the corresponding AGCM responses, followed by discussions on maintenance mechanisms. Section 4 gives a summary and additional discussions.

\section{Data and numerical experiments}

\section{a. Observational data}

Atmospheric variables, including sea level pressure (SLP), geopotential height, air temperature, horizontal wind and pressure velocity, diabatic heating rates, and surface turbulent heat fluxes are obtained from the new Japanese 55-year Reanalysis of the global atmosphere (JRA-55; Kobayashi et al. 2015; Harada et al. 2016) for the period $1958-2010$ available on a $1.25^{\circ} \times 1.25^{\circ}$ grid. In addition, the following two SST datasets are used. One is the climatological-mean SST field for each calendar month derived from the National Oceanic and Atmospheric Administration (NOAA) Optimum Interpolation Sea Surface Temperature (OISST), into which SST data from satellite observations and in situ observations are blended since November 1981 (Reynolds et al. 2007). Assigned on a $0.25^{\circ} \times 0.25^{\circ}$ grid, the data can resolve the finescale structure of the SAFZ. Meanwhile, anomalous SST fields associated with the decadal-scale SAFZ variability have been derived from in situ surface marine observations by ships and buoys that have been compiled in the International Comprehensive Ocean Atmosphere Dataset (ICOADS; Worley et al. 2005) for the period 1960-2011. Thanks to its longer data period, ICOADS can cover both the prominent positive and negative events of the decadal-scale SAFZ variability (Fig. 1b). With no horizontal interpolation added, the ICOADS data can represent decadal-scale SST anomalies confined to the SAFZ (Figs. 1a,c). In the gridded ICOADS SST data, some low-quality measurements are known to be included over the central North Pacific 
(Minobe and Maeda 2005), which have been removed through subjective quality control by Y. Tanimoto of Hokkaido University (Tanimoto et al. 1997; Iwasaka and Hanawa 1990).

\section{b. AGCM experiments}

The present study uses an AGCM for the Earth Simulator (AFES; Ohfuchi et al. 2004, 2007; Enomoto et al. 2008; Kuwano-Yoshida et al. 2010) with a horizontal resolution of T119 spectral truncation (equivalently $110-\mathrm{km}$ grid intervals) and 56 vertical levels up to the 0.1-hPa level. Though not particularly high, this resolution is the same as that of the atmospheric component of the CGCM used in Taguchi et al. (2012) and typical among models used for climatic projection. With this horizontal resolution, both the pronounced SST gradient and meridionally confined SST anomalies in the SAFZ, if prescribed as the model boundary condition, can be resolved reasonably well. In fact, the same AGCM with the T119 truncation was successful in reproducing a basin-scale anticyclonic anomaly observed in October 2011 in response to SST anomalies around the SAFZ, as shown in Okajima et al. (2014), where details of AFES, including parameterization schemes, are described.

A pair of ensemble experiments has been conducted with AFES. One is a control experiment (CTRL), in which AFES is forced with the climatological-mean monthly SST and sea ice cover derived from OISST. The other is the positive experiment (POS), for which the SST field for AFES is constructed in such a way that only the positive decadal SST anomaly observed along the SAFZ has been added to the climatologicalmean field. In the present study, the SAFZ is marked as the trapezoidal region $\left(35^{\circ}-42^{\circ} \mathrm{N}, 140^{\circ} \mathrm{E}\right.$ and $38^{\circ}-$ $50^{\circ} \mathrm{N}, 173^{\circ} \mathrm{W}$ ) in Fig. $1 \mathrm{a}$, where the SST variability is particularly large. In fact, the area-averaged SST anomaly over the region clearly shows decadal variability in winter (Fig. 1b). The periods in which the 5-yr mean of the area-averaged wintertime SST were highest (from 1967/68 to 1971/72) and lowest (from $1983 / 84$ to $1987 / 88$ ) are defined as representative periods for the positive and negative phases of the decadal SST variability. The SST anomaly for a given calendar month is defined as half of the local difference of ICOADS SST between the two epochs. Because the purpose of this study is to examine the mechanisms for maintaining a large-scale atmospheric response, which requires a robust model response, the SST anomaly (viz., half of the difference between the two epochs, from $1967 / 68$ to $1971 / 72$ and from $1983 / 84$ to $1987 / 88$ ) observed along the SAFZ has been multiplied by 3 . The SST anomaly assigned thus becomes as strong as $2^{\circ}-3^{\circ} \mathrm{C}$ and comparable in magnitude to those actually observed by satellites in October 2011 and prescribed for the experiment by Okajima et al. (2014). The inflation of the SST anomaly may be justified in recognition of the tendency for the ICOADS data to underestimate the magnitude of SST anomalies as measured by satellites. As an example, Fig. 1c shows the SST anomaly in January prescribed for the POS experiment.

Each of these two experiments (CTRL, POS) comprises 40 members, whose initial conditions were derived from the model output simulated for 1 October 2011 of the individual ensemble members of the control experiment by Okajima et al. (2014), whose initial conditions were taken from the JRA-25 data (Onogi et al. 2007) for individual days from 27 May to 5 June 2011. Ten members are integrated from the model output on 1 October 2011. Another 10 members are integrated with the same model executable file and initial conditions as the first 10 members, but on an updated Earth Simulator system with newer processors. Integrations on the two systems become diverse after a few weeks as a result of the chaotic nature of the simulated atmosphere, and therefore we can consider them as independent members. Yet, we have confirmed that the ensemble-mean fields are similar between the two sets. For another 20 members, initial conditions have been obtained as the fields after integrating the 10 outputs on 1 October 2011 for one day or two. Each member is integrated until the end of the subsequent March, with daily SST fields interpolated linearly in time from its monthly fields. Deviations of the ensemblemean atmospheric fields simulated in the POS experiment from the CTRL counterpart are regarded as the model atmospheric response to the positive SST anomaly associated with the decadal SAFZ variability, and their robustness is assessed locally by the $t$ statistic. In this paper, the January responses as well as observed anomalies are investigated, which are strongest during the winter.

The present study also utilizes the 120-yr CGCM integration analyzed by Taguchi et al. (2012). The coupled model is the CGCM for the Earth Simulator (CFES), consisting of AFES with horizontal resolution of T119 spectral truncation and 48 vertical levels up to the $1-\mathrm{hPa}$ level and the Coupled Ocean-Sea Ice Model for the Earth Simulator (OIFES; Komori et al. 2005) with $0.5^{\circ}$ grid intervals and 54 vertical levels. Although mesoscale oceanic eddies are unresolved with this configuration, CFES can still simulate a prominent oceanic frontal zone in the North Pacific that marks the boundary between the subtropical and subpolar gyres, which corresponds to the SAFZ. Details of CFES, including 
(a) JRA55 JAN Z300

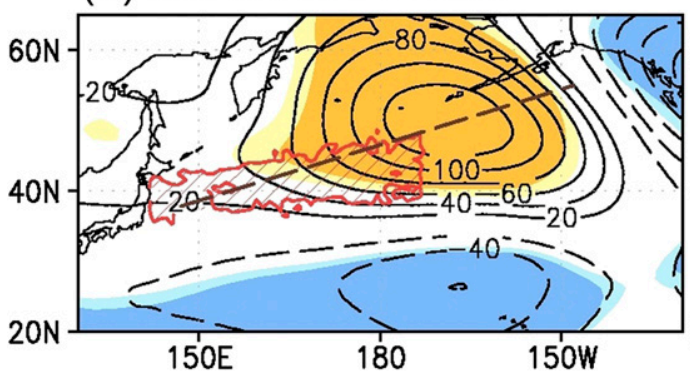

(b) JRA55 JAN SLP

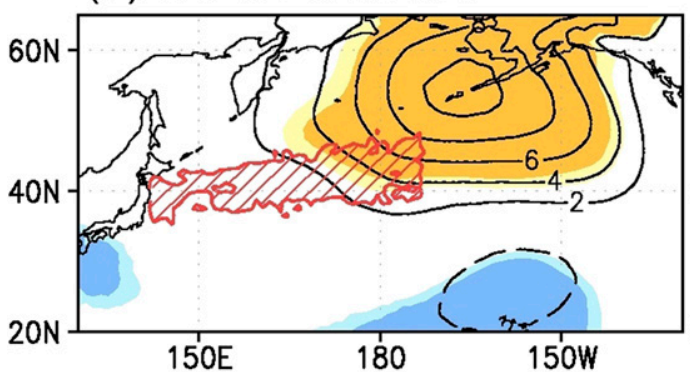

(c) POS JAN Z300

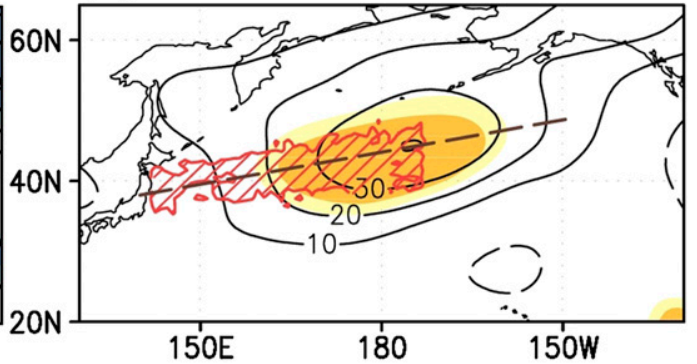

(d) POS JAN SLP

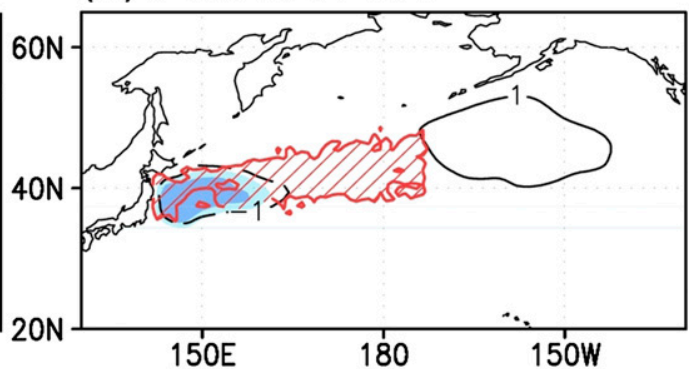

FIG. 2. January anomalies of (a) Z300 (contoured every $20 \mathrm{~m}$; dashed for negative values) and (b) SLP (contoured every $2 \mathrm{hPa}$; dashed for negative values) based on JRA-55, obtained as half of their composited differences between the positive and negative phases of the decadal SAFZ variability. Their signs correspond to those for the positive phase. Red hatches indicate SST anomalies exceeding $+0.5^{\circ} \mathrm{C}$. (c),(d) As in (a) and (b), respectively, but for the ensemble response in the POS experiment. The contour interval is $10 \mathrm{~m}$ in (c) and $1 \mathrm{hPa}$ in (d). Red hatches indicate SST anomalies exceeding $+1.5^{\circ} \mathrm{C}$. Light and heavy shading indicates statistical significance at the $90 \%$ and $95 \%$ confidence levels, respectively. Dashed lines in (a) and (c) are those along which vertical sections in Figs. 3a and 3b, respectively, are constructed.

parameterization schemes, are described in Taguchi et al. (2012).

\section{Results}

\section{a. Structure of the circulation anomalies/responses in midwinter}

Figures $2 \mathrm{a}$ and $2 \mathrm{~b}$ show maps of the January anomalies of 300-hPa height (Z300) and SLP, respectively, observed over the North Pacific as their differences between the positive (1967/68-1971/72) and negative (1983/84-1987/88) phases of the decadal SAFZ variability (Nakamura et al. 1997; Taguchi et al. 2012). In these panels and hereafter, the magnitude of the observed difference is halved, so as to represent the typical amplitude of "anomalies" for the positive phase, which is characterized by a positive SST anomaly in the SAFZ. The remote influence from other ocean basins is considered to be weak (see appendix). Over the midlatitude North Pacific, a well-defined basin-scale anticyclonic anomaly was observed in both the lower and upper troposphere, which resembles the PNA pattern defined by Wallace and Gutzler (1981). The corresponding response in the POS experiment is shown in Figs. 2c and $2 \mathrm{~d}$. Though weaker in magnitude and shifted slightly southwestward, the upper-tropospheric anticyclonic anomaly is simulated (Fig. 2c) as an ensemble response to the warm SST anomaly in the SAFZ. In the lower troposphere (Fig. 2d), however, the anticyclonic response south of Alaska is not statistically significant, while a cyclonic response simulated around Japan extends eastward over the warm SAFZ.

In agreement with Taguchi et al. (2012), the observed anticyclonic anomaly features an equivalent barotropic structure accompanied by a warm anomaly in the troposphere (Fig. 3a). The POS experiment also simulates the nearly equivalent barotropic structure in its response (Fig. 3b). As pointed out by Taguchi et al. (2012), the anticyclonic anomalies, both in the observations and the POS experiment, also include a weak baroclinic component, marked by southwestward tilts of phase lines with height (note that cross sections in Fig. 3 are constructed along the dashed lines in Figs. 2a,c). These tilts are indicative of a possible conversion of available potential energy (APE) from the 


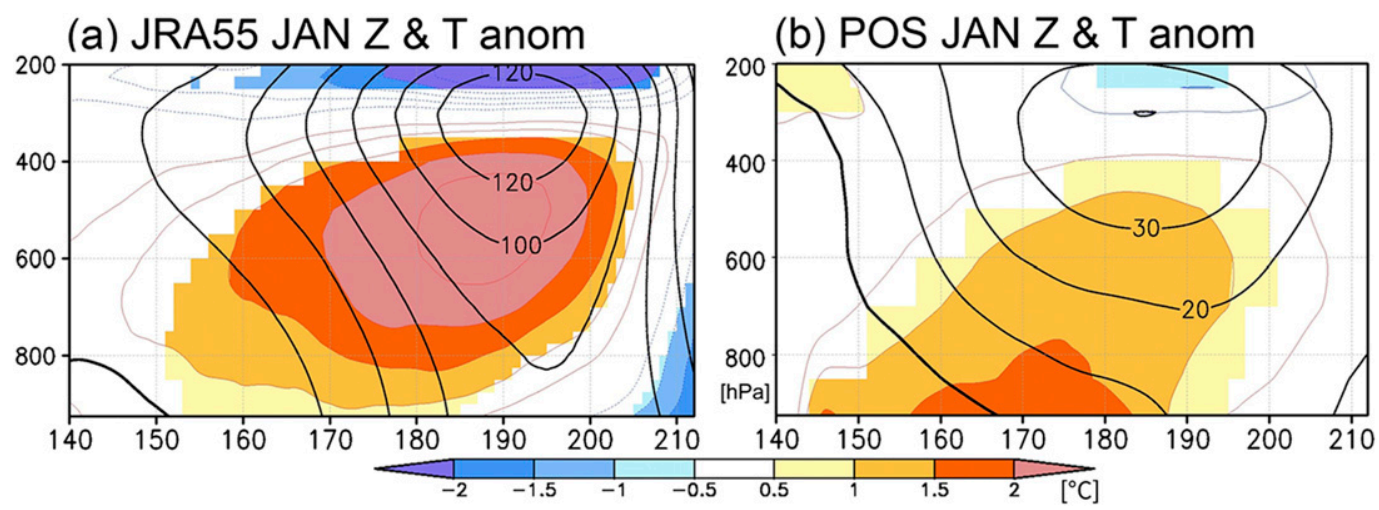

FIG. 3. Vertical section of January anomalies in temperature (colored as indicated; shaded only for significant anomalies at the $90 \%$ confidence level) and geopotential height [contoured in black every $20 \mathrm{~m}$ in (a) and $10 \mathrm{~m}$ in (b)] in the (a) observations and (b) POS experiment, along straight lines as indicated with dashed lines in Figs. 2a and 2c, respectively. The observed anomalies have been obtained as in Figs. 2a and 2b.

climatological-mean temperature gradient into the anomalies, as discussed later.

Figures $4 \mathrm{a}$ and $4 \mathrm{~b}$ show January anomalies in total precipitation and 600-hPa vertical motion in JRA-55. Precipitation was significantly enhanced just over the warm SST anomaly, consistent with anomalous upward motion. These local features indicate forcing from the underlying warm SST and are well simulated in our model experiment (Figs. $4 \mathrm{c}$ and $4 \mathrm{~d}$ ). However, the model fails to capture observed suppressed precipitation and anomalous downward motion downstream of the SST anomaly.

Figure 5 illustrates anomalous January storm-track activity in both the upper and lower troposphere observed and simulated in the presence of the warm SST anomalies in the SAFZ. In the observations, the stormtrack activity weakens mainly downstream of the warm SAFZ (Figs. 5a,b), in addition to its very weak enhancement north of the climatological low-level storm track. These anomalies indicate a poleward deflection of the storm track associated with the stationary anticyclonic anomaly (Fig. 2). The deflection seems consistent with the decadal shift of the SAFZ (Nakamura and Kazmin 2003), which acts to anchor the storm track by maintaining the near-surface baroclinic zone (Nakamura et al. 2004; Hotta and Nakamura 2011). The weakening of the storm-track activity associated with the northward shift of the oceanic front is consistent with Kwon and Joyce (2013). In our CTRL simulation (Figs. 5c,d), the climatological-mean strength and position of the Pacific storm track (purple contours) are overall in agreement with the observations, although the model storm track is displaced southward slightly and extends farther downstream. The observed weakening of the upper-tropospheric storm-track activity is simulated, though seemingly rather modest, downstream of the warm SAFZ (Fig. 5c) in the POS experiment. That experiment also simulates the poleward deflection of the lower-tropospheric storm track (Fig. 5d). Unlike in the observations, however, the model's lowertropospheric storm-track activity is suppressed markedly to the south of the warm SAFZ SST anomaly (Fig. 5d) but not downstream, which is consistent with the reduced lower-tropospheric baroclinicity.

\section{b. Maintenance of monthly anomalies in the observation and model}

Taguchi et al. (2012) suggested a possible contribution of the feedback forcing from anomalous transient eddy activity along the Pacific storm track onto the observed weakening of the Aleutian low associated with the warm SAFZ SST anomaly. To assess this contribution, eddy feedback forcing has been evaluated locally as a geopotential height tendency derived from anomalous eddy vorticity and heat fluxes, as in Lau and Holopainen (1984) and Nishii et al. (2009):

$$
\begin{aligned}
\frac{\partial \bar{z}}{\partial t}= & \frac{1}{g}\left[\nabla^{2}+f^{2} \frac{\partial}{\partial p}\left(\frac{1}{\sigma} \frac{\partial}{\partial p}\right)\right]^{-1} \\
& \times\left\{-f \nabla \cdot\left(\overline{v^{\prime \prime} \zeta^{\prime \prime}}\right)+f^{2} \frac{\partial}{\partial p}\left[\frac{-\nabla \cdot\left(\overline{v^{\prime \prime} \theta^{\prime \prime}}\right)}{-\frac{\partial \Theta}{\partial p}}\right]\right\} \\
\sigma= & -\frac{\partial \Theta}{\partial p} \frac{R}{p}\left(\frac{p}{p_{00}}\right)^{R / c_{p}}
\end{aligned}
$$

where the notations are standard unless noted otherwise. In (1), quantities with double primes signify high-frequency 
(a) JRA-55 JAN precip

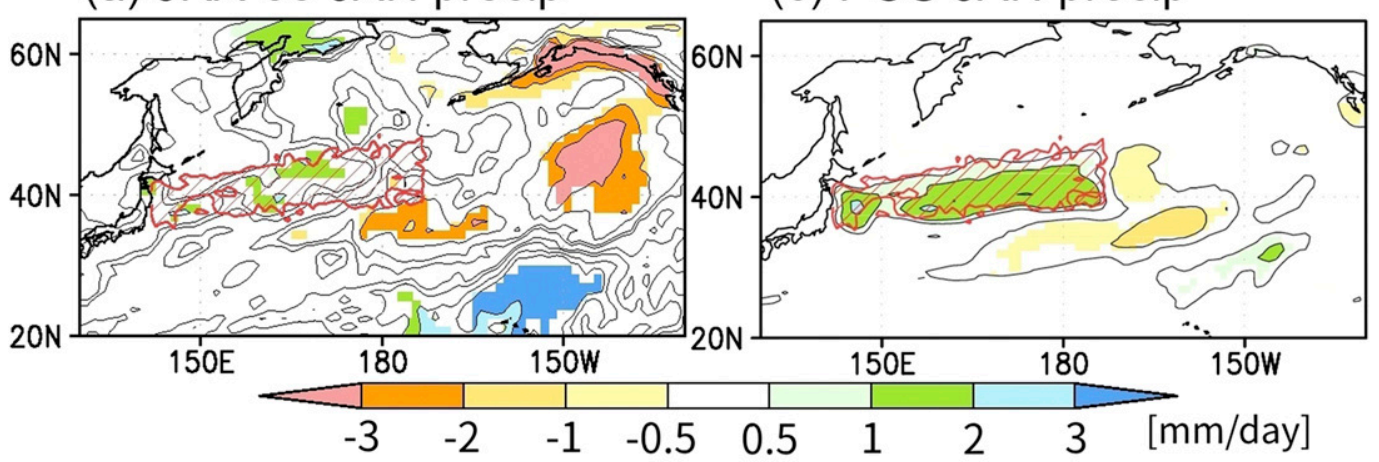

(b) JRA-55 JAN $\omega 600$

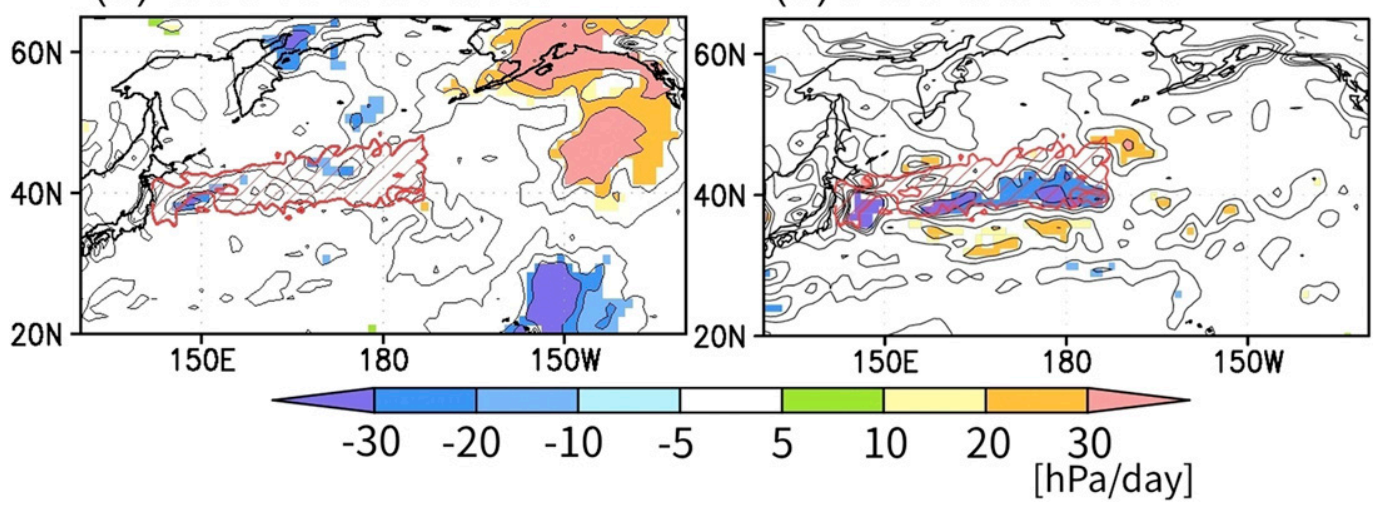

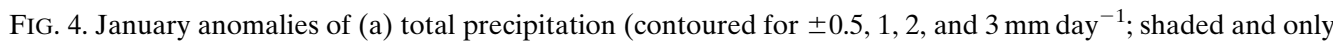
for significant anomalies at the $90 \%$ confidence level) and (b) $600-\mathrm{hPa}$ vertical motion (contoured for $\pm 10,20$, and $30 \mathrm{hPa} \mathrm{day}^{-1}$; colored as indicated and only for significant anomalies at the $90 \%$ confidence level) based on JRA-55. Red hatches indicate SST anomalies exceeding $+0.5^{\circ} \mathrm{C}$. (c),(d) As in (a) and (b), respectively, but for the ensemble response in the POS experiment. Red hatches indicate SST anomalies exceeding $+1.5^{\circ} \mathrm{C}$.

fluctuations associated with transient eddies, which were estimated locally from 6-hourly deviations from 5-day running means. Quantities with overbars represent monthly mean values. In addition, submonthly quasistationary fluctuations whose period is longer than a week, including blocking anomalies, can also exert feedback forcing on monthly mean anomalies. Their forcing was estimated from local deviations of the 5-day running means from the monthly mean fields in a manner analogous to (1). Since those high- and low-frequency transients keep exerting feedback forcing onto the background state in which they are embedded, climatologically this feedback forcing must be compensated for by other processes. Height tendencies have been computed through (1) from the JRA-55 data and model output, and the effective feedback forcing on monthly anomalies is therefore evaluated from the anomalous height tendency after removing the climatological-mean tendency.

As shown in Figs. 6a and 6b, transient eddies migrating along the Pacific storm track, as the net, act to reinforce the anticyclonic anomaly observed over the North Pacific. The anomalous height tendency by these feedback forcings is so efficient that it could replenish the observed monthly anticyclonic anomaly within a week or so in both the lower and upper troposphere. The anomalous eddy vorticity flux acts to induce an anticyclonic tendency in both the upper and lower troposphere as a positive feedback forcing. Meanwhile, the anomalous eddy heat flux acts to induce anomalous cyclonic and anticyclonic tendencies in the upper and lower troposphere, respectively (not shown), consistent with Lau and Nath (1991). The POS experiment captures the observed eddy feedback forcing anomaly but in a substantially smaller magnitude (Figs. $6 \mathrm{c}$ and $6 \mathrm{~d}$ ). The weaker forcing is attributable partly to the weaker model anticyclonic response (Fig. 2). In addition, the induced anomalous height tendency does not coincide well with the height response, suggesting that transient eddy feedback forcing is not quite efficient in maintaining the simulated monthly response. Anomalous feedback forcing from submonthly quasi-stationary 
(a) JRA55 JAN V'V'300 RMS

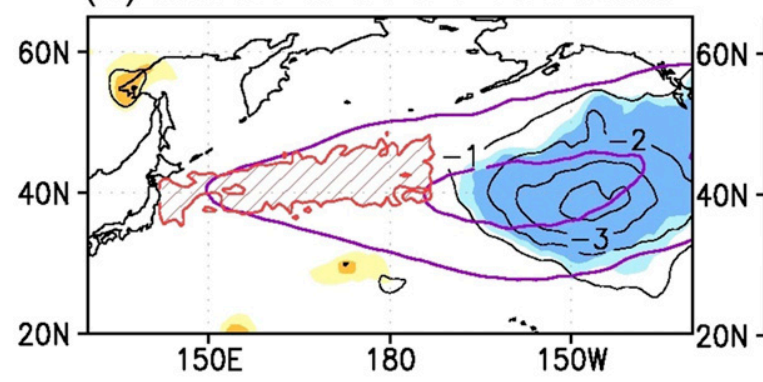

(b) JRA55 JAN v'T'850

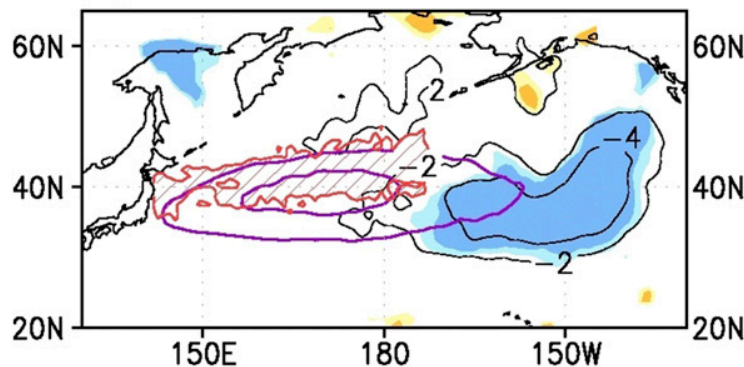

(c) POS JAN V'V'300 RMS

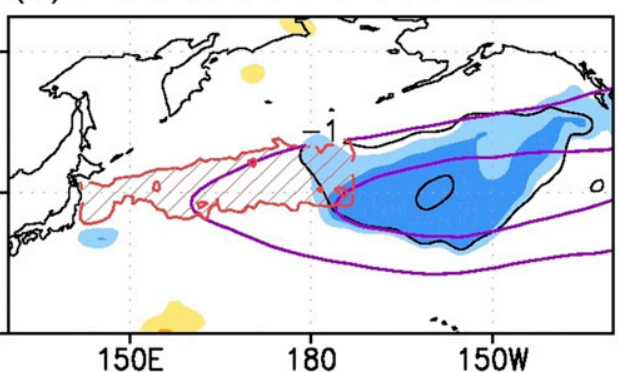

(d) POS JAN v'T'850

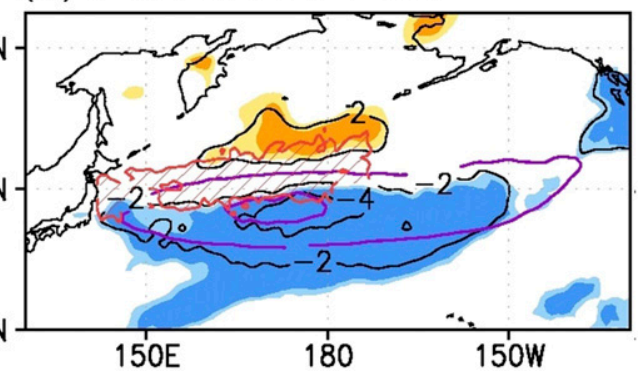

FIG. 5. (a) Climatological (purple contours for 12 and $16 \mathrm{~m} \mathrm{~s}^{-1}$ ) and anomalous (black contours every $1 \mathrm{~m} \mathrm{~s}^{-1}$ ) rootmean-square of January high-pass-filtered $300-\mathrm{hPa}$ meridional wind velocity, as a measure of upper-tropospheric storm-track activity. (b) Climatological (purple contours for 15 and $20 \mathrm{~m} \mathrm{~K} \mathrm{~s}^{-1}$ ) and anomalous (black contours every $2 \mathrm{~m} \mathrm{~K} \mathrm{~s}^{-1}$ ) poleward heat flux based on high-pass-filtered 850-hPa wind velocities and temperature, as a measure of lower-tropospheric storm-track activity; (a) and (b) are based on JRA-55, obtained as their composited differences between the positive and negative phases of the decadal SAFZ variability. Their signs correspond to those for the positive phase. Red hatches indicate SST anomalies warmer than $+0.5^{\circ} \mathrm{C}$. Light and heavy shading indicates statistical significance at the $90 \%$ and $95 \%$ confidence levels, respectively. (c),(d) As in (a) and (b), respectively, but for the ensemble response of the POS experiment. Red hatches indicate SST anomalies exceeding $+1.5^{\circ} \mathrm{C}$.

fluctuations is inefficient in both the observations and POS experiment (not shown).

The anticyclonic anomaly in the observations and simulated response exhibits westward (and slightly southward) tilted phase lines with height (Figs. 2 and 3). These baroclinic structures imply possible APE conversion from the baroclinic westerly jet into the monthly anomalies. In addition, the southwestward-tilted structure implies additional APE conversion from the zonal land-sea contrast in temperature near the Okhotsk Sea and Kuril Islands (Tanaka et al. 2016). Furthermore, the monthly circulation anomalies can convert kinetic energy (KE) from the background westerlies (Hoskins et al. 1983; Simmons et al. 1983; Nakamura et al. 1987; Kosaka and Nakamura 2006).

To evaluate contributions from the energy conversion processes and assess their importance relative to diabatic heating and the transient eddy feedback forcing, the following energy budget analysis has been performed for both the observed anomalies and simulated response. Efficient energy conversion relative to generation, if any, suggests self-maintenance of the anomalies.
In the following, APE and KE associated with monthly mean anomalies are defined as

$$
\mathrm{APE}=\frac{R}{p S_{p}}\left(\frac{T^{\prime 2}}{2}\right) \quad \text { and } \quad \mathrm{KE}=\frac{u^{\prime 2}+v^{\prime 2}}{2},
$$

respectively, where primes signify anomalies as deviations from their climatological means denoted with subscripts $c$. The climatological means of atmospheric quantities for JRA-55 are defined as an average over 1982-2010 for consistency with the climatologicalmean SST prescribed in the model. For the model, climatological means are defined as ensemble means of the CTRL experiment. Other notations are standard. The energy conversion/generation terms are expressed as

$$
\begin{aligned}
& \mathrm{CK}=\frac{v^{\prime 2}-u^{\prime 2}}{2}\left(\frac{\partial u_{c}}{\partial x}-\frac{\partial v_{c}}{\partial y}\right)-u^{\prime} v^{\prime}\left(\frac{\partial u_{c}}{\partial y}+\frac{\partial v_{c}}{\partial x}\right) \\
& \mathrm{CP}=\frac{R}{p S_{p}}\left(-u^{\prime} T^{\prime} \frac{\partial T_{c}}{\partial x}-v^{\prime} T^{\prime} \frac{\partial T_{c}}{\partial y}\right)
\end{aligned}
$$


(a) JRA55 JAN Z300

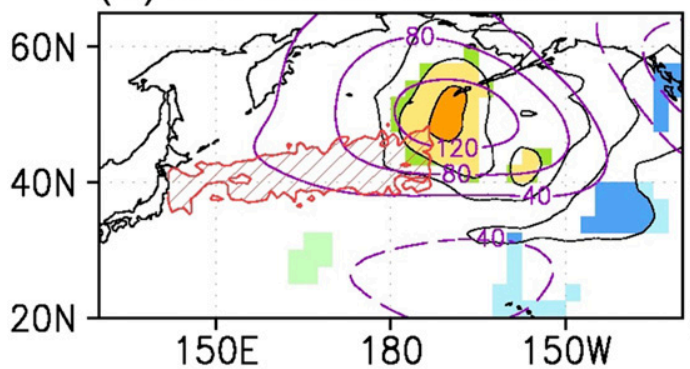

(b) JRA55 JAN Z850

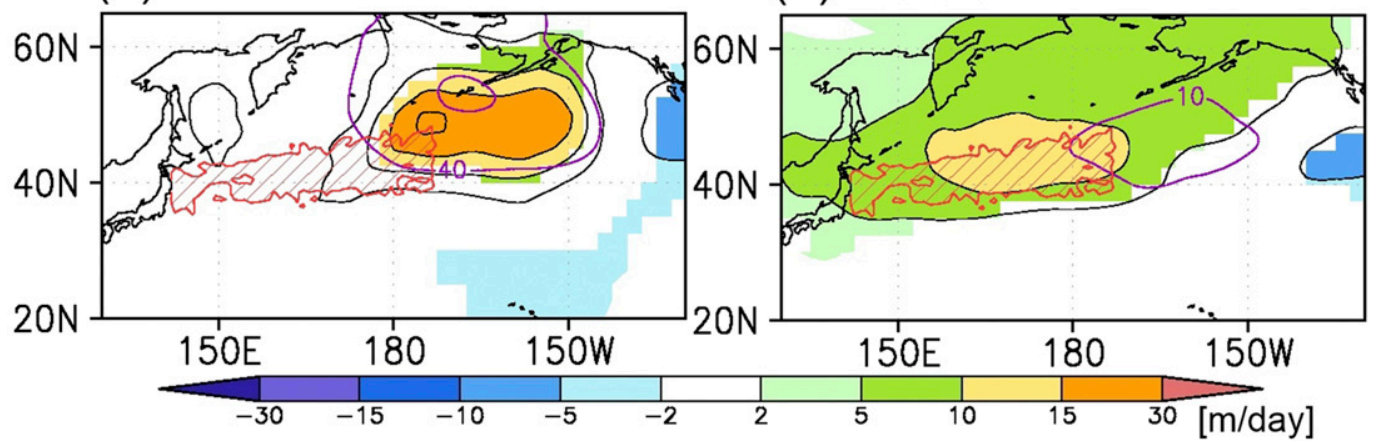

(c) POS JAN Z300

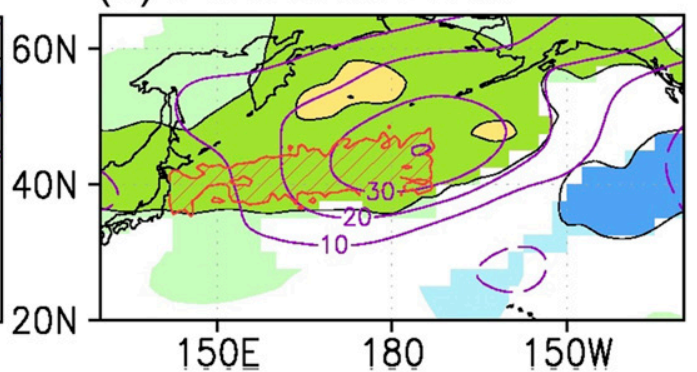

(d) POS JAN Z850

FIG. 6. (a) Anomalous geopotential height tendency for January ( $\mathrm{m} \mathrm{day}^{-1}$; contoured in black; shaded only for significant anomalies at the $90 \%$ confidence level) induced by anomalous heat and vorticity fluxes associated with high-frequency transient eddies, superimposed on January 300-hPa height anomalies (contoured in purple every $40 \mathrm{~m}$; dashed for negative values), based on JRA-55. Red hatches indicate positive SST anomalies exceeding $+0.5^{\circ} \mathrm{C}$. (b) As in (a), but for the 850-hPa geopotential height tendency and anomaly. (c),(d) As in (a) and (b), respectively, but for the ensemble response of the POS experiment (contour interval of $10 \mathrm{~m}$ ). Red hatches indicate SST anomalies exceeding $+1.5^{\circ} \mathrm{C}$.

$$
\begin{aligned}
\mathrm{GP} & =\frac{R}{p S_{p} C_{p}} T^{\prime} Q^{\prime} \\
\mathrm{CK}_{\mathrm{HF}} & =u^{\prime}\left[-\frac{g}{f} \frac{\partial}{\partial y}\left(\frac{\partial \bar{z}^{\prime}}{\partial t}\right)\right]+v^{\prime}\left[\frac{g}{f} \frac{\partial}{\partial x}\left(\frac{\partial \bar{z}^{\prime}}{\partial t}\right)\right], \text { and } \\
\mathrm{CP}_{\mathrm{HF}} & =-\frac{g}{S_{p}} T^{\prime}\left[\frac{\partial}{\partial p}\left(\frac{\partial \bar{z}^{\prime}}{\partial t}\right)\right] .
\end{aligned}
$$

In the above equations, $\mathrm{CK}$ denotes the barotropic $\mathrm{KE}$ conversion, $\mathrm{CP}$ is the baroclinic APE conversion, and GP is the APE generation through diabatic processes. In (3d) and (3e), subscripts HF denote the conversion from high-frequency transient eddies, and $\partial \bar{z}^{\prime} / \partial t$ denotes the anomalous monthly height tendency defined in (1) as the feedback forcing from submonthly fluctuations on monthly anomalies. These energy conversion and generation terms are then integrated vertically from the surface to the 100-hPa level.

In January, a meridional dipole of circulation anomalies is observed east of the warm SST anomaly (Fig. 7a). The anomaly dipole straddles the exit region of the upper-tropospheric westerly jet (gray contours in Fig. 7a), where the KE conversion (CK) into the monthly anomaly is particularly large through the anomalous easterlies. The POS experiment yields a similar spatial distribution of $\mathrm{CK}$, although substantially weaker in accordance with the weak circulation response (Fig. 7c). In fact, $\mathrm{CK}_{x}[\mathrm{CK}$ associated with the diffluent climatological-mean westerlies, represented as the first term on the RHS of (3a)] dominates over $\mathrm{CK}_{y}$ [CK associated with the lateral shear of the climatological-mean westerlies; the second term on the RHS of (3a)] in both the observations (Fig. 8a) and POS experiment (Fig. 8b). The observed dipole-like anomalies feature the PNA pattern, which is maintained efficiently through the $\mathrm{KE}$ conversion within the jet exit region (Nakamura et al. 1987; Feldstein 2002).

In association with the observed PNA-like anomalies, $\mathrm{CP}$ is particularly large over the midlatitude North $\mathrm{Pa}$ cific and Gulf of Alaska, in addition to western Canada and Alaska (Fig. 7b). In the POS experiment (Fig. 7d), $\mathrm{CP}$ maximizes along the westerly Pacific jet where the 
(a) JRA55 JAN CK

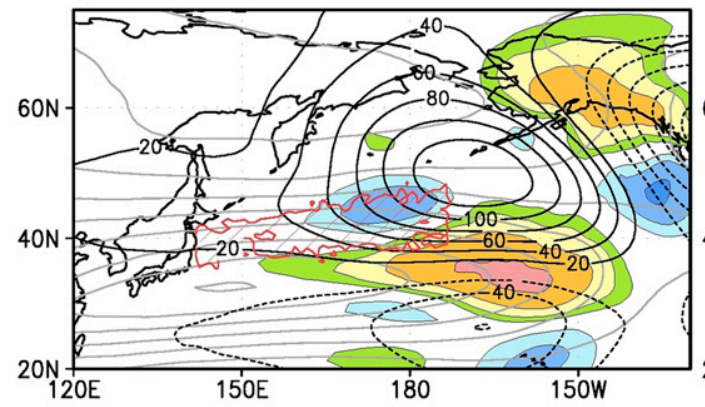

(b) JRA55 JAN CP

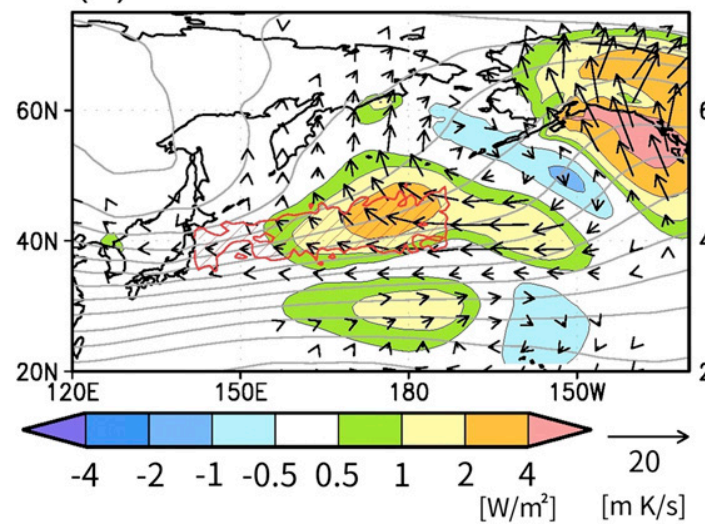

(c) POS JAN CK

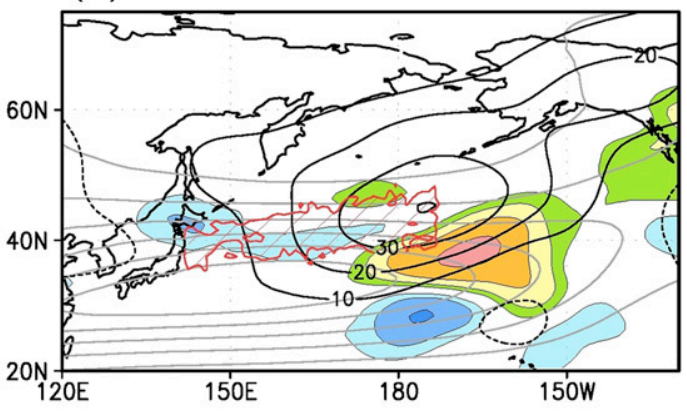

(d) POS JAN CP

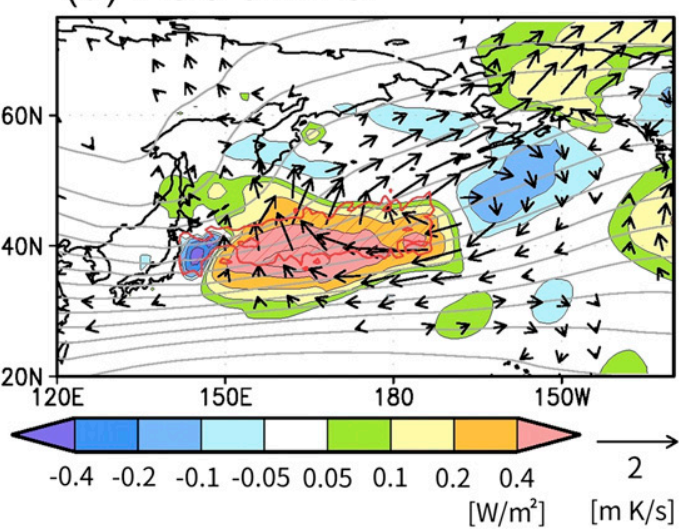

FIG. 7. (a) CK from the climatological-mean state into the January monthly anomalies integrated vertically from the surface to $100 \mathrm{hPa}\left(\mathrm{W} \mathrm{m}^{-2}\right.$; colored as indicated), superimposed upon the monthly $\mathrm{Z} 300$ anomaly (black contours every $20 \mathrm{~m}$; dashed for negative anomalies) and the climatological-mean 300-hPa westerly wind velocity (gray contours every $10 \mathrm{~m} \mathrm{~s}^{-1}$, thick contour for $50 \mathrm{~m} \mathrm{~s}^{-1}$ ). (b) As in (a), but for CP into the monthly anomalies from the climatological-mean state, superimposed upon the climatological-mean $700-\mathrm{hPa}$ temperature (gray contours every $3^{\circ} \mathrm{C}$, thick contours every $15^{\circ} \mathrm{C}$ ) and 700 -hPa temperature flux associated with the monthly anomalies (arrows; $\mathrm{K} \mathrm{m} \mathrm{s}^{-1}$ ). Red hatches indicate SST anomalies exceeding $+0.5^{\circ} \mathrm{C}$; (a) and (b) are for January based on JRA-55. (c),(d) As in (a) and (b), respectively, but for the ensemble response in the POS experiment. Contour interval is $10 \mathrm{~m}$ in (c). Red hatches indicate SST anomalies exceeding $+1.5^{\circ} \mathrm{C}$.

climatological-mean meridional temperature gradient is pronounced. As evident in Fig. $8 \mathrm{~b}, \mathrm{CP}_{y}$ [CP associated with the meridional temperature gradient; the second term on the RHS of (3b)] dominates over $\mathrm{CP}_{x}[\mathrm{CP}$ associated with zonal temperature gradient; the first term on the RHS of (3b)] in the POS experiment. By contrast, $\mathrm{CP}_{x}$ and $\mathrm{CP}_{y}$ are comparable in the observed anomalies (Fig. 8a).

The "efficiency" of a particular energy conversion or generation process in (3) can be evaluated by dividing it by total energy (as the sum of APE and KE) associated with monthly anomalies:

$$
\text { conversion efficiency } \equiv \frac{\text { energy conversion term }}{\mathrm{APE}+\mathrm{KE}} \text {. }
$$

This conversion (or generation) efficiency $\left(\mathrm{day}^{-1}\right)$ is based on spatially integrated total energy and three-dimensionally integrated conversion/generation terms. Here, energy conversion/generation is integrated horizontally over the North Pacific $\left(25^{\circ}-65^{\circ} \mathrm{N}, 140^{\circ} \mathrm{E}-140^{\circ} \mathrm{W}\right)$, while the $\mathrm{KE}$ and $\mathrm{APE}$ are integrated hemispherically $\left(20^{\circ}-90^{\circ} \mathrm{N}\right)$, both after being vertically integrated from the surface to the 100-hPa level (Kosaka and Nakamura 2006). Since $\mathrm{KE}$ and APE are positive definite quantities, integrating over a wider domain leads to conservative estimates of the efficiency. In contrast, energy conversion and generation are subject to contamination if integrated over a too-wide domain, as it would take in the conversion and generation arising from insignificant, physically unrelated anomalies. By limiting the area to the North Pacific, we can avoid such noise. The reciprocal of the efficiency therefore gives a measure of how long it would take to replenish the hemispherically integrated total energy of a particular monthly anomaly pattern solely by a particular conversion/generation process over the North 
(a) JRA-55

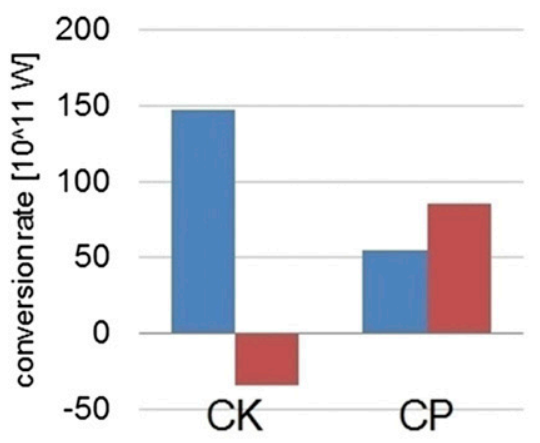

(b) AFES

20

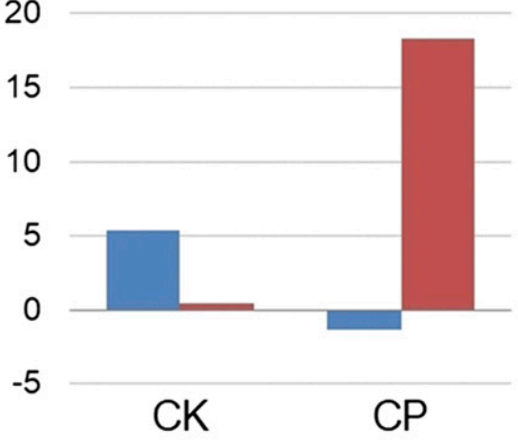

(c) CFES

160

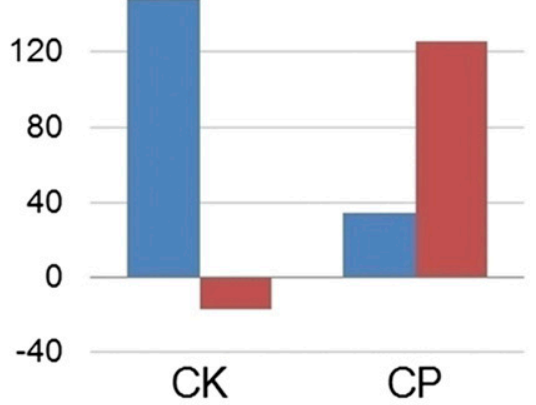

FIG. 8. (a) Bar graphs of the energy conversion terms $\mathrm{CK}_{x}$ (blue), $\mathrm{CK}_{y}$ (red), $\mathrm{CP}_{x}$ (blue), and $\mathrm{CP}_{y}$ (red) (defined in the text), integrated vertically from the surface to $100-\mathrm{hPa}$ and then horizontally over the North Pacific $\left(25^{\circ}-65^{\circ} \mathrm{N}, 140^{\circ} \mathrm{E}-140^{\circ} \mathrm{W}\right)$. Evaluated for the January anomalies shown in Figs. 2 and 3 based on JRA-55. (b) As in (a), but for the POS experiment. (c) As in (a), but for the long-term CFES integration.

Pacific. Table 1 summarizes the efficiency thus evaluated for each of conversion and generation processes.

For the anomalies observed in January, contributions from $\mathrm{CK}, \mathrm{CP}$, and the net transient eddy forcing (TE in Table 1) based on the JRA-55 data are important for the maintenance of the monthly anomalies, consistent with the aforementioned height tendency analysis. In particular, $\mathrm{CK}$ and $\mathrm{CP}$ are so efficient that they can replenish the total energy over the Northern Hemisphere only in 10 days or so. The net contribution from the feedback forcing by transient eddies along the storm track is positive but to a lesser degree, as it can replenish the hemispheric energy nearly in a month. This positive contribution is through efficient barotropic feedback forcing from transient eddies. Diabatic processes (GP), including longwave radiation, act to damp the observed thermal anomalies.

In the POS experiment, $\mathrm{CP}$ is the most efficient process for the maintenance of the response in January, whose conversion efficiency is about $0.08 \mathrm{day}^{-1}$ (Table 1), while CK is less efficient. The particularly efficient $\mathrm{CP}$ in the model seems consistent with the well-defined baroclinic structure of the anticyclonic response, whose westward-tilting structure seems more apparent than in the observed anomalies (Fig. 3). The maintenance through TE is as efficient as in the observations. These results indicate that the energy conversion from the background state is most efficient for the maintenance of the observed anomaly pattern and model response. This is suggestive of their characteristics as a "dynamical mode" (Kosaka and Nakamura 2006, 2010), which is inherent to the climatological-mean state of the westerly jet, planetary waves, and associated background thermal gradient. Among the energy conversion/generation terms, the most distinct difference between the observations and the model appears in GP (energy generation through diabatic heating). For the observed anomalies GP as the net is negative and acts as a damping, while positive GP in the model indicates efficient forcing to the response. This discrepancy arises mainly from differences in the anomalous turbulent heat flux and precipitation. As shown in Fig. 9a, the anomalous surface turbulent heat flux based on the JRA-55 data is nearly zero over the warm SST anomaly and weakly negative to the east. The diminished anomalous surface heat flux indicates cancelation between anomalous upward heat

TABLE 1. Efficiency $\left(\mathrm{day}^{-1}\right)$ and the corresponding time scale (days) with which a given conversion or generation process integrated vertically from the surface to the $100-\mathrm{hPa}$ level and over the North Pacific $\left(25^{\circ}-65^{\circ} \mathrm{N}, 140^{\circ} \mathrm{E}-140^{\circ} \mathrm{W}\right)$ could replenish the total energy $($ as the sum of KE and APE) of a given monthly atmospheric anomaly pattern integrated three-dimensionally over the extratropical Northern Hemisphere. Efficient processes with time scales less than 30 days are highlighted in bold. Negative values indicate a dissipative process or the conversion through which a monthly anomaly pattern gives up energy to the climatological-mean state. The evaluation was performed separately for the January anomaly patterns shown in Fig. 2 based on JRA-55 and the ensemble AFES response.

\begin{tabular}{|c|c|c|c|c|c|c|c|c|}
\hline & & & CK & $\mathrm{CP}$ & GP & $\mathrm{CK}_{\mathrm{HF}}$ & $\mathrm{CP}_{\mathrm{HF}}$ & $\mathrm{TE}$ \\
\hline \multirow[t]{2}{*}{ JRA-55 } & Jan & Efficiency $\left(\right.$ day $\left.^{-1}\right)$ & 0.0886 & 0.111 & -0.0266 & 0.0458 & -0.0101 & 0.0357 \\
\hline & & Time scale (days) & 11.3 & 8.98 & -37.6 & 21.8 & -99.3 & 28.0 \\
\hline \multirow[t]{2}{*}{ AFES } & Jan & Efficiency $\left(\right.$ day $\left.^{-1}\right)$ & 0.0271 & 0.0783 & 0.0756 & $\mathbf{0 . 0 3 3 3}$ & 0.0126 & 0.0459 \\
\hline & & Time scale (days) & 36.9 & 12.8 & 13.2 & 30.0 & 79.6 & 21.8 \\
\hline
\end{tabular}


(a) JRA-55 JAN THF

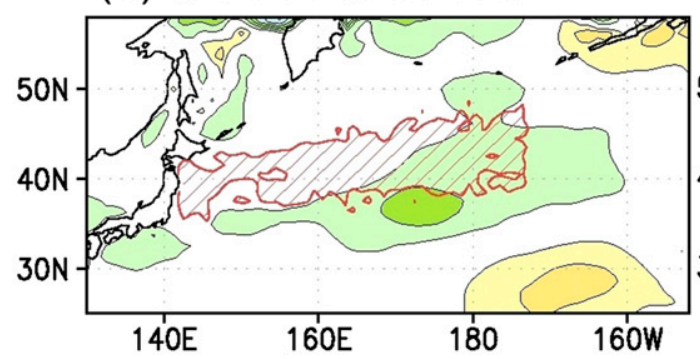

(c) CFES JAN THF (b) POS JAN THF

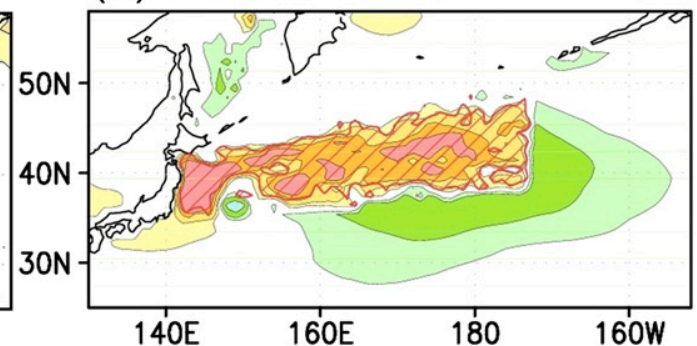

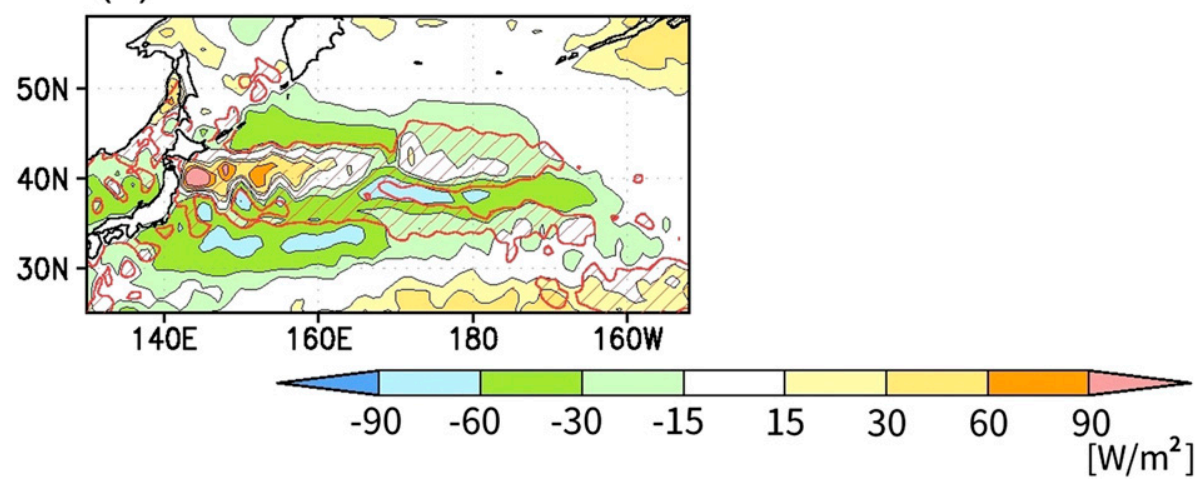

FIG. 9. (a) January anomalies of the net surface turbulent heat flux (colored as indicated) based on JRA-55. Positive values indicate heat released from the ocean. (b) As in (a), but for the ensemble response in the POS experiment. (c) As in (a), but based on the long-term CFES integration. Red hatches indicate positive SST anomalies exceeding $+0.5^{\circ} \mathrm{C}$ in (a) and (c) and $+1.5^{\circ} \mathrm{C}$ in (b).

flux tendency due to the local warm SST anomaly and an offsetting contribution from the anomalous surface easterlies associated with the anticyclonic anomalies (Fig. 2b) that act to suppress the heat/moisture release. In the POS experiment, by contrast, the surface anticyclonic response and associated anomalous surface easterlies are quite weak (Fig. 2d), leading to enhanced heat release from the (inflated) SST anomaly prescribed (Fig. 9b). As evident in Fig. 4c, the strong positive precipitation response is confined into the region over the prescribed SST anomaly, where the lower and midtroposphere are anomalously warm (Fig. 3b). These discrepancies are likely attributable to the different causality between the observations and AGCM experiment (cf. Sutton and Mathieu 2002). In the POS experiment, by design, GP should be positive since the SAFZ SST anomaly is the cause of the atmospheric response via thermal forcing. In the observations, by contrast, the SST anomalies (including the warm anomaly around the SAFZ) are a mixture of forcing on, and response to, the atmospheric anomalies, and anomalous surface heat fluxes cannot necessarily be determined by the SST anomalies.

Maintenance mechanisms for the atmospheric anomalies associated with the decadal-scale SAFZ variability in the long-term CGCM integration analyzed by Taguchi et al. (2012) are also examined by applying the same analysis as above. Here, atmospheric anomalies have been extracted in the same manner as for JRA-55. Figure 10 shows January anomalies of Z300 and SLP thus extracted from the positive and negative phases (26-30 and 56-60 model years, respectively) of the model SAFZ variability. The equivalent barotropic anticyclonic anomaly is in good agreement with the corresponding signal in Taguchi et al. (2012, their Figs. 10b and 10c). The pattern in the CFES simulation resembles the observed pattern more than the AFES response. Enhanced precipitation and anomalous upward motion over the warm SST anomaly is also consistent with the observations and POS experiment (Fig. 11). The anomalous turbulent heat flux is similar to the observational counterpart, except for larger upward heat flux anomaly in the western part of the SST anomaly due probably to the larger SST anomaly in CFES $\left(2^{\circ}-3^{\circ} \mathrm{C}\right.$; Taguchi et al. 2012) than in the observations (Fig. 9c). Table 2 summarizes the same energetic analysis as above applied to the monthly anomalies in CFES, and GP is missing owing to the lack of diabatic heating data in the model output. The transient eddy feedback forcing acts to reinforce the monthly mean anticyclonic anomaly in both 
(a) CFES Z300 JAN

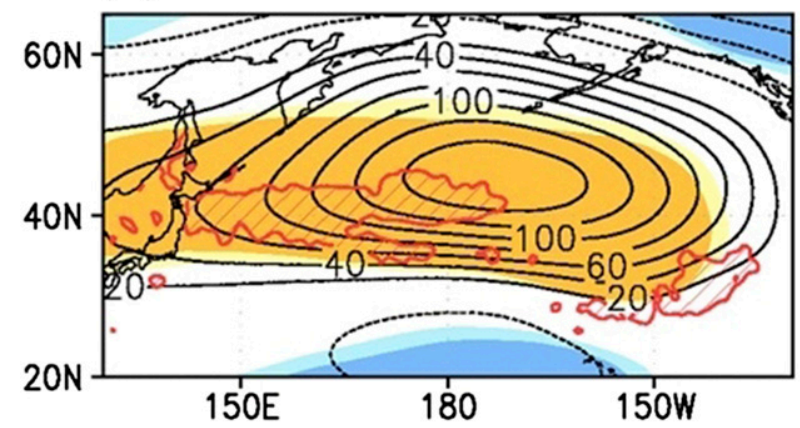

(b) CFES SLP JAN

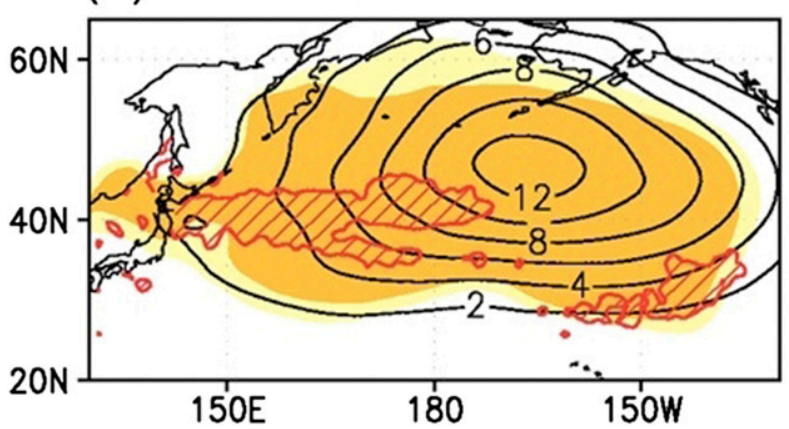

FIG. 10. As in Figs. 2a and 2b, but based on the long-term CFES integration. Their signs correspond to the positive phase.

the upper and lower troposphere as observed (Fig. 12), although with slightly lower efficiency (Table 2). As in the observations, contributions from $\mathrm{CK}$ and $\mathrm{CP}$ are most important in the maintenance of the monthly anomalies (Table 2). As in the observations, $\mathrm{CK}_{x}$ dominates over $\mathrm{CK}_{y}$, which is consistent with the PNAlike structure of the anomaly (Fig. 8c). The $\mathrm{CP}_{y}$ is much more efficient than $\mathrm{CP}_{x}$. The efficiency of $\mathrm{CK}$ and $\mathrm{CP}$ is so high that, if combined, they can replenish the total energy over the entire Northern Hemisphere within a week. These results are suggestive of characteristics as a dynamical mode of the atmospheric anomalies in CFES.

\section{c. Relationship with atmospheric internal variability}

It is informative to examine the dominant patterns of atmospheric internal variability, which can play an important role in determining a response to SST anomalies (Peng and Robinson 2001). For JRA-55 and CFES, atmospheric internal variability can be estimated as intraseasonal variability (deviations from 3-month running means) as in Zheng et al. (2000). This method can exclude a substantial fraction of the remote influence from ENSO (figure not shown). For AGCM, intermember spread around the ensemble mean for the (a) CFES JAN precip

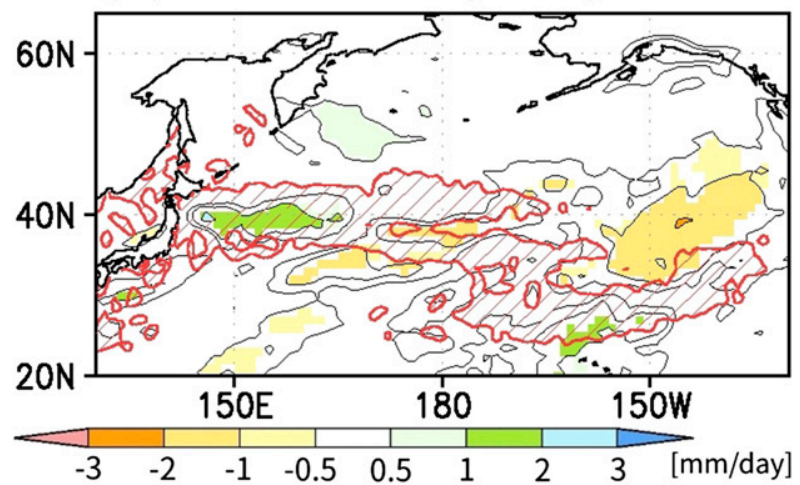

(b) CFES JAN $\omega 600$

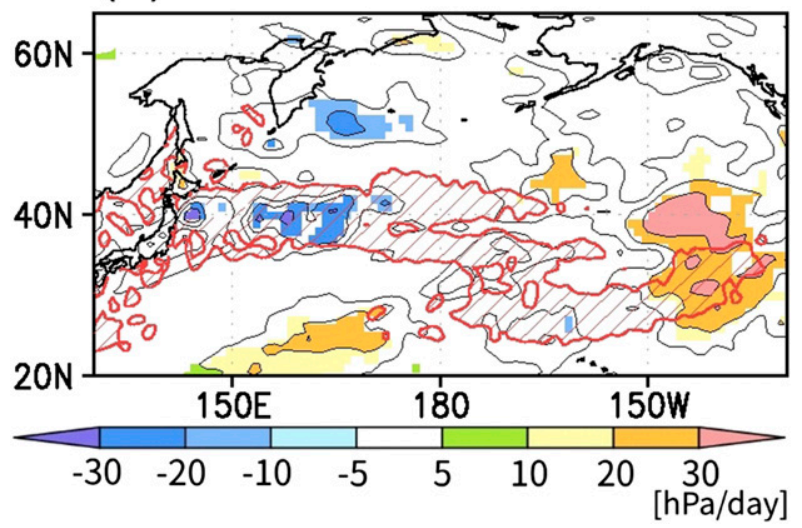

FIG. 11. As in Figs. 4a and 4b, but based on the long-term CFES integration.

CTRL experiment can be considered as internal variability.

In JRA-55, the atmospheric internal variability in January maximizes immediately south of the Aleutian Islands in the vicinity of the primary center of action of the PNA pattern (Fig. 13a). The monthly anticyclonic anomaly observed with the decadal SAFZ variability thus corresponds well to the atmospheric dominant internal variability. The situation is essentially the same in the CFES integration (Fig. 13b), although the strong variability area spreads too far northeastward. The leading empirical orthogonal function (EOF) patterns in the observations and CFES apparently correspond to the PNA pattern, with a slight displacement of their centers (Figs. 13d,e). Note that EOF patterns capture a mixture of internal variability and remote influence. When calculated based on the interannual variability of intraseasonal anomalies, leading EOF patterns are still similar in structure (not shown). In AFES (Fig. 13c), by contrast, there is no single maximum of internal variability over the North Pacific due to a substantially 
TABLE 2. As in Table 1, but for the anomaly pattern extracted from the CFES integration as shown in Fig. 10. Evaluation of GP is not available.

\begin{tabular}{cccccc}
\hline \hline & $\mathrm{CK}$ & $\mathrm{CP}$ & $\mathrm{CK}_{\mathrm{HF}}$ & $\mathrm{CP}_{\mathrm{HF}}$ & $\mathrm{TE}$ \\
\hline CFES Jan Efficiency & $\mathbf{0 . 0 7 9 2}$ & $\mathbf{0 . 0 9 6 1}$ & 0.0254 & -0.0132 & 0.0122 \\
(day $^{-1}$ ) & & & & & \\
$\begin{array}{c}\text { Time scale } \\
\text { (days) }\end{array}$ & $\mathbf{1 2 . 6}$ & $\mathbf{1 0 . 4}$ & 39.4 & -75.8 & 82.2 \\
\hline
\end{tabular}

weaker PNA-like variability. Instead, it yields dual maxima, with one maximum located over the eastern Okhotsk Sea and the other in the eastern North Pacific (around $38^{\circ} \mathrm{N}, 160^{\circ} \mathrm{W}$ ). Indeed, the intermember leading EOF of the 40-member CTRL experiment features a zonally elongated north-south dipole pattern, and its northern lobe extends westward along $\sim 60^{\circ} \mathrm{N}$ (Fig. 13f), reminiscent of the western Pacific (WP) pattern, whose northern center of action is located at $60^{\circ} \mathrm{N}, 155^{\circ} \mathrm{E}$ (Wallace and Gutzler 1981). The inherent weakness of the internal PNA variability may contribute to the weak AFES response to the SAFZ SST anomaly.

\section{Summary and discussion}

In the present study, a pair of AGCM ensemble experiments has been conducted to investigate mechanisms for the maintenance of a wintertime large-scale atmospheric response to warm SST anomalies associated with the decadal-scale poleward displacement of the North Pacific SAFZ. The January signal observed with the decadal variability of the SAFZ features an anticyclonic anomaly in equivalent barotropic structure that strongly resembles the PNA pattern. A similar signal is captured also in a long-term CGCM integration. An ensemble sensitivity AGCM experiment (i.e., POS experiment) is driven by the decadal-scale positive SST anomaly observed along the SAFZ superposed climatological-mean SST. It simulates a significant upper-tropospheric basin-scale anticyclonic response over the North Pacific, although with weaker amplitude than the observed. Pacific storm-track activity is modulated in an overall consistent manner between the observations and POS experiment. In both, uppertropospheric storm-track activity weakens east of the warm SST anomaly over the SAFZ while in the lower troposphere its axis shifts northward.

Maintenance mechanisms for the observed anomalies and simulated responses are investigated in detail through an energy budget analysis. The PNA-like monthly anticyclonic anomaly in January associated with the northward shift of the SAFZ efficiently maintains itself through the APE conversion from the

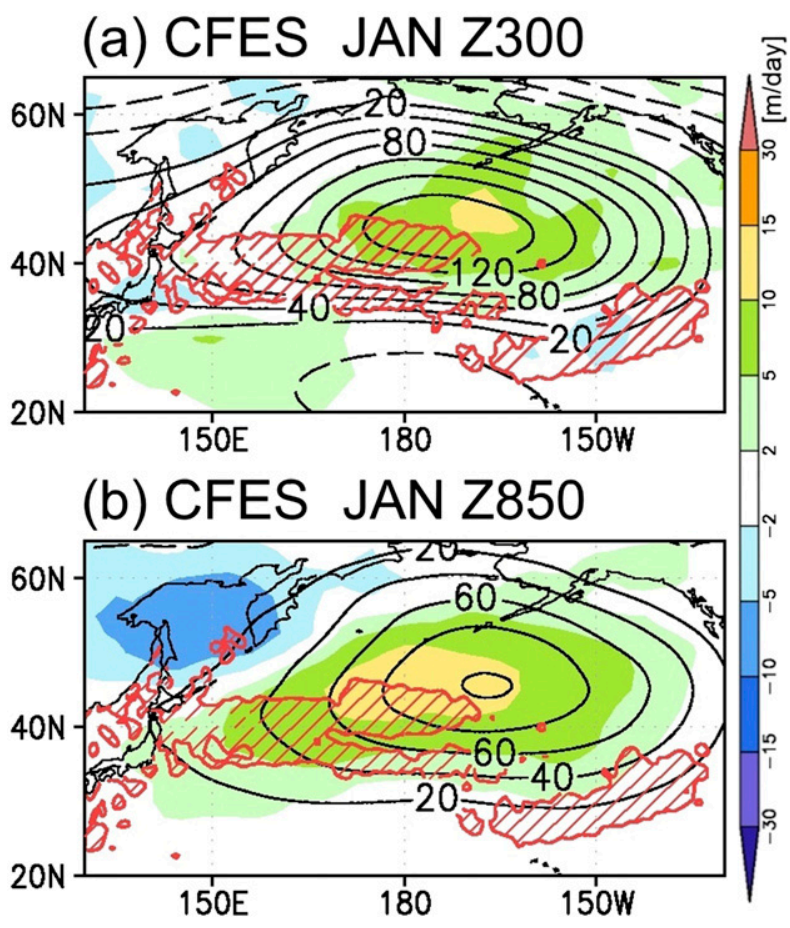

FIG. 12. As in Figs. 6a and 6b, but based on the long-term CFES integration.

climatological-mean state (CP) in the observations, CGCM integration, and the POS experiment. Realized under the strong meridional temperature gradient across the climatological Pacific jet and the zonal temperature gradient associated with the planetary waves, $\mathrm{CP}$ in the North Pacific is efficient enough to replenish the total energy associated with the PNA-like observed anomalies and model response within two weeks or less. Those anomalies and model response in January thus have some characteristics as a preferred mode (or dynamical mode) of variability over the wintertime North Pacific. In the observations and CGCM integration, the KE conversion from the climatological westerly jet (CK) also contributes significantly to the maintenance of the monthly anomaly, while it is less efficient than $\mathrm{CP}$ in the POS experiment. The feedback forcing from transient eddies (TE) due to the modulated storm-track activity also contributes to the maintenance of the observed anomaly and simulated response. The APE generation through diabatic processes (GP) differs fundamentally between the POS experiment and observations: GP is efficient in the former while it works as a weak dissipation in the latter, a difference traceable to the difference in turbulent heat flux and precipitation anomalies.

The present study has also investigated the relationship of the atmospheric anomalies and AGCM response 
(a) JRA55 JAN Z300

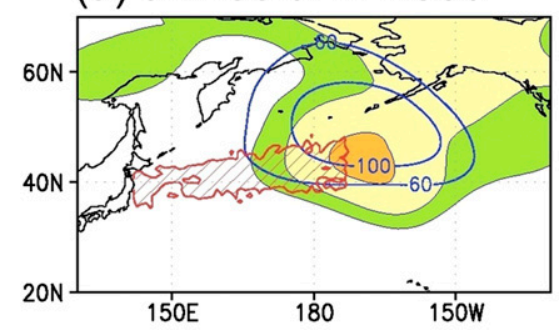

(b) CFES JAN Z300

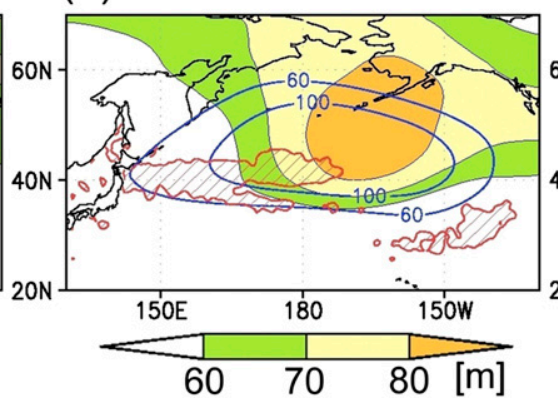

(c) AFES JAN Z300

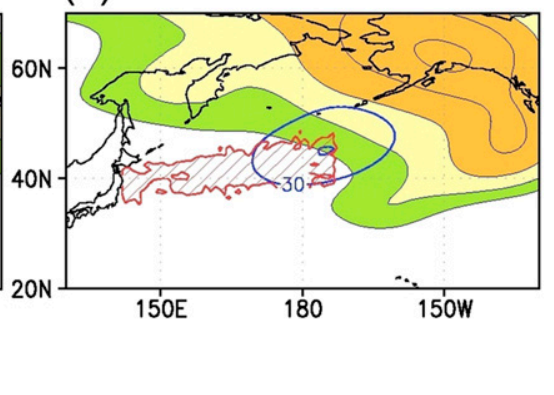

(d) JRA55 JAN EOF1

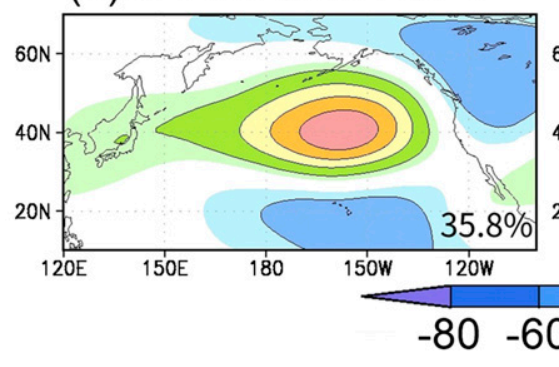

(e) CFES JAN EOF1

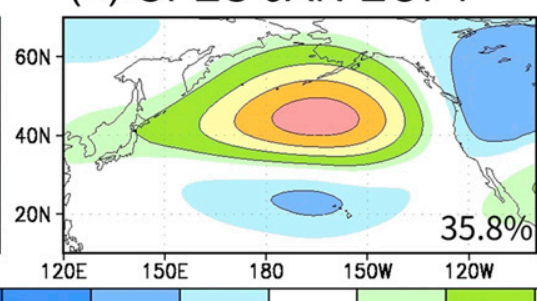

(f) AFES JAN EOF1

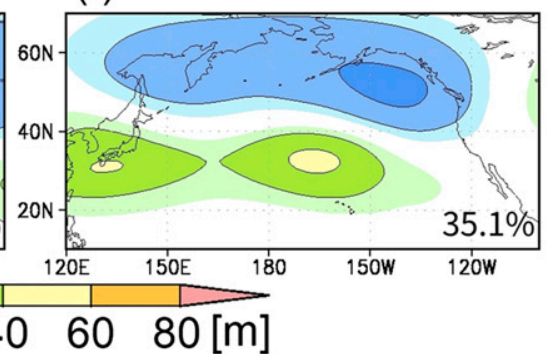

FIG. 13. (a) Climatological interannual standard deviation of intraseasonal Z300 anomalies in January for the period of 1982-2010, based on JRA-55. (b) As in (a), but based on the long-term CFES integration. (c) Intermember standard deviation of January Z300 in the CTRL experiment. The observed or simulated anticyclonic anomaly in January is indicated with blue contours [for 60 and $100 \mathrm{~m}$ in (a) and (b) and for 30 and $40 \mathrm{~m}$ in (c)]. Red hatches indicate positive SST anomalies exceeding $+0.5^{\circ} \mathrm{C}$ in (a) and (b) and $+1.5^{\circ} \mathrm{C}$ in (c). (d) The first EOF mode of January Z300 within the domain shown, based on JRA-55 in 1982-2010. (e) As in (a), but based on the long-term CFES integration for the period 1-120 model year. (f) Intermember EOF1 of the 40-member CTRL experiment for January within the domain shown. Numbers in the bottom-right corner in (d), (e), and (f) indicate explained variance fractions.

to atmospheric internal variability. Both in the reanalysis data and CGCM integration, dominant internal variability defined as deviations from the 3-month running mean resembles the PNA pattern. In the AFES experiments, however, the magnitude of the internal variability is weaker around the primary center of action of the PNA pattern. As the atmospheric internal variability was suggested to play an important role in forming a response to SST anomalies (Peng and Robinson 2001), the weaker response in the AFES may be attributable in part to the weaker PNA-like internal variability. The link between atmospheric internal variability and the observed signal or the simulated response may be a key to understanding the model dependency of the atmospheric response to midlatitude SST anomalies and will be further investigated in our future work.

Previous works have suggested that the atmospheric response to the SAFZ SST anomaly has a prominent intraseasonal variation. Using a few types of atmospheric models, Peng et al. (1997) and Peng and Whitaker (1999) showed that the response was shallow cyclonic in January but deep anticyclonic in February and attributed it to differences in transient eddy feedback forcing. Liu et al. (2007) found that the atmospheric anomaly associated with the warm SAFZ SST anomaly was PNA-like in early winter while significantly weaker in late winter in their ensemble CGCM experiment. Taguchi et al. (2012) also suggested such weakening in February from reanalysis data and a CGCM experiment. In our AGCM experiment, the anticyclonic response was simulated in February near the center of the January response and seasonal weakening was subtle (not shown). The seasonality is an issue to be investigated in future studies.

In the present paper, the maintenance mechanisms that are particularly effective in a moderate horizontal resolution $\left(\sim 1.0^{\circ}\right)$ model are investigated. Although the prescribed SST forcing is inflated artificially, the simulated response in the POS experiment is qualitatively similar to the observational counterpart. It is worth emphasizing that the observed signal is not a genuine response to the SST anomaly but rather a mixture of the response to, and a forcing on, the SST anomaly, and hence the simulated response does not necessarily match the observed anomaly pattern completely. The weaker model response may be due to a misrepresentation of the atmospheric internal variability and the lack of air-sea coupling in the model as well as remote forcings that could possibly be included in the 
observations. In our AGCM with $\sim 1.0^{\circ} \times 1.0^{\circ}$ horizontal resolution, the most effective maintenance mechanism is energy conversion from the climatological background state along with efficient transient feedback forcing, and diabatic processes are also important. This implies that a moderate-resolution $\left(\sim 1.0^{\circ}\right) \mathrm{AGCM}$ is able to simulate a basin-scale atmospheric response to the SAFZ SST anomaly through synoptic- and basin-scale dynamical processes, a complementary view to the study by Smirnov et al. (2015), who found that a robust anticyclonic response with realistic strength was simulated only in their higher-resolution $\left(0.25^{\circ} \times 0.25^{\circ}\right)$ AGCM against a warm SST anomaly in the SAFZ with realistic strength. They claimed that diabatic processes associated with cumulus convection that can be better represented in their highresolution model are critical for the robust basin-scale atmospheric response. Interestingly, our AGCM response is anticyclonic to the east of the warm SST anomaly, which is qualitatively similar to their higherresolution AGCM result, although the prescribed SST anomaly needs to be inflated in the present study to obtain a robust response. The weak amplitude in our AGCM response is presumably related to its insufficient ability to represent mesoscale precipitation systems and the lack of daily variability in the background SST (Zhou et al. 2015, 2017). The former can be important for efficiently triggering a robust basin-scale response to a warm SST anomaly in the SAFZ by sensitively modulating the Pacific storm-track activity. Resolution dependence of the model atmospheric response to the SAFZ variability will be investigated in future study.

Acknowledgments. The authors thank Justin Small for giving us valuable comments. We also thank two anonymous reviewers for their useful and constructive comments that have led our paper to its substantial improvement. This study is supported in part by the Japanese Ministry of Education, Culture, Sports, Science and Technology (MEXT) through a Grant-in-Aid for Scientific Research in Innovative Area 2205 and through the Arctic Challenge for Sustainability (ArCS) Program and by the Japanese Ministry of Environment through the Environment Research and Technology Department Fund 2-1503. This work was also supported by the Japan Society for the Promotion of Science (JSPS) through KAKENHI Grants 15J04846 for JSPS Research Fellows and $16 \mathrm{H} 01844$ and by the Japan Science and Technology Agency through Belmont Forum CRA "InterDec." S. O. is also supported by MEXT through the Program for Leading Graduate Schools. The Earth Simulator was utilized in support of JAMSTEC. The JRA-55 reanalysis dataset is provided by JMA. NOAA Optimum Interpolation SST data (OISST) are provided by the

\section{(a) COBE SST JAN}

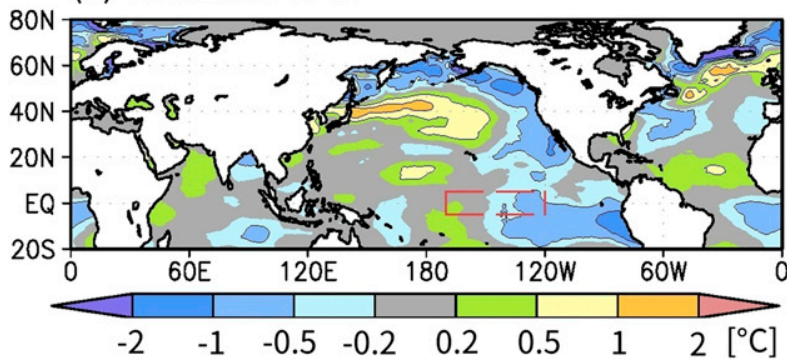

(b) COBE-SST JAN regr/corr

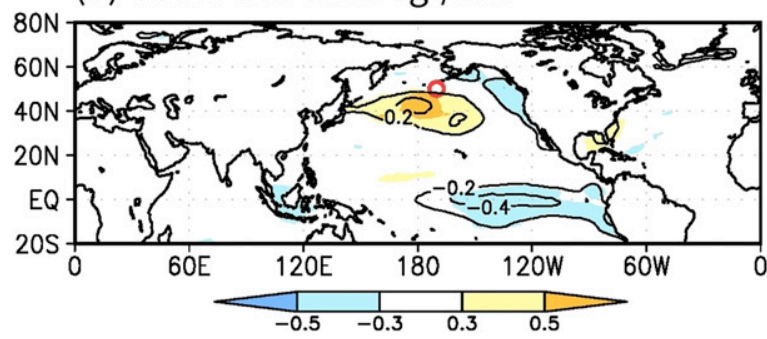

FIG. A1. (a) January SST anomaly $\left({ }^{\circ} \mathrm{C}\right.$; color) extracted as half of the difference between the positive and negative phases of decadal variability of the SAFZ. The red dashed line box indicates the Niño-3.4 domain. (b) Map of the simultaneous one-point regression of SST (contoured every $0.2^{\circ} \mathrm{C}$ ) onto the January Z300 anomaly based on JRA-55 at the reference point $\left(50^{\circ} \mathrm{N}, 170^{\circ} \mathrm{W}\right.$; red open circle) for the period 1958-2012. The corresponding correlation is superimposed with color shading. Based on COBE-SST.

NOAA-CIRES Climate Diagnostics Center, Boulder, Colorado, from their website (http://www.cdc.noaa.gov/). The Grid Analysis and Display System (GrADS) was used for drawing figures.

\section{APPENDIX}

\section{Evaluation of Remote Influence}

The observed signal (shown, e.g., in Fig. 2) can be in part influenced by remote forcing, including ENSO. However, it is difficult to obtain SST fields in the tropics with high reliability from the gridded ICOADS data used in this study for the period around 1970, when the negative phase of the decadal SAFZ variability was observed. Instead, the Centennial In Situ ObservationBased Estimates of SSTs (COBE-SST; Ishii et al. 2005) and ERSST.v3b (Smith et al. 2008) are utilized. It is found that these two datasets yield very similar results. In the following, the statistics based on COBE-SST are presented, which was prescribed as the boundary condition for the JRA-55 reanalysis used in this study. The following results are based on simultaneous correlation/ regression, but similar results are obtained when a one or two month lag (ocean leads atmosphere) is taken. Figure A1a shows a map of January SST anomalies 


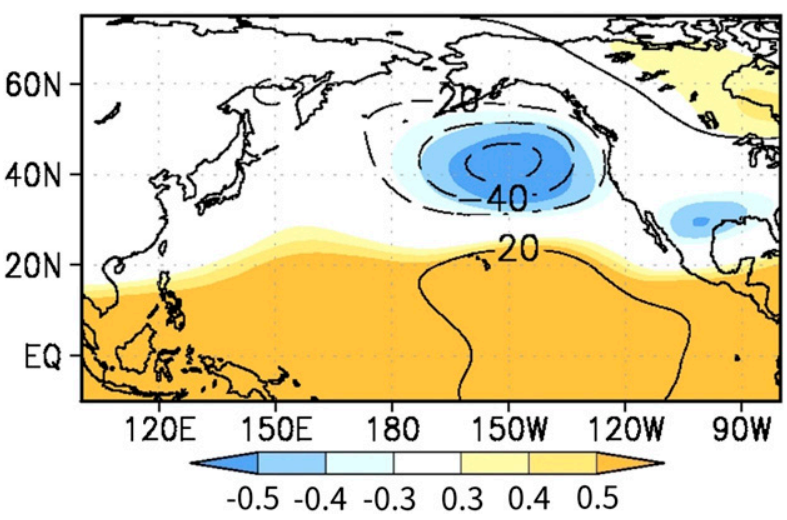

FIG. A2. Simultaneous linear regression anomalies (contoured every $20 \mathrm{~m}$; dashed for negative values) and correlation (colored as indicated) of January Z300 onto the Niño-3.4 index based on JRA55 and COBE-SST for 1958-2012. Note that the sign of the local height anomaly corresponds to the El Niño condition, and it should be reversed under the La Niña-like condition shown in Fig. A1a.

based on COBE-SST at a $1^{\circ}$ horizontal resolution, which has been obtained as half of the difference between the positive and negative phases of decadal variability of the SAFZ. Defined in the same manner, Fig. A1a offers a quasi-global view of the SST anomalies shown in Fig. 1c. The warm SST anomaly along the North Pacific SAFZ tends to be observed concomitantly in a weak La Niñalike situation, which potentially affects the atmospheric anomalies shown in Fig. 2 remotely.

As a brief assessment of the remote forcing from the La Niña-like condition, Fig. A2 shows a map of 300-hPa height anomalies in January regressed linearly onto interannual SST anomalies averaged within the Niño-3.4 domain (Niño-3.4 index hereafter) for the period 19582012. The corresponding correlation is superimposed with shading. A significant cyclonic anomaly tends to be observed in the eastern North Pacific, whose amplitude is about $60 \mathrm{~m}$ for a $1.0^{\circ} \mathrm{C} \mathrm{SST}$ anomaly within the Niño3.4 domain. The atmospheric anomaly resembles the tropical Northern Hemisphere (TNH) pattern (Mo and Livezey 1986). Given that the January Niño-3.4 index was $-0.183^{\circ} \mathrm{C}$ in our composite shown by Fig. A1a, the particular remote influence can yield a positive Z300 anomaly of +10 or $15 \mathrm{~m}$ over the eastern North Pacific. This anomaly magnitude is substantially smaller, and its center $\left(\sim 40^{\circ} \mathrm{N}, 150^{\circ} \mathrm{W}\right)$ is displaced from the observed anomaly center $\left(\sim 50^{\circ} \mathrm{N}, 170^{\circ} \mathrm{W}\right.$; Fig. $\left.2 \mathrm{a}\right)$. These results suggest that the remote influence from the tropics was weak. In fact, anomaly Z300 maps are almost unchanged from Fig. 2 even when the remote influence based on the Niño-3.4 index has been removed statistically. Nevertheless, the results presented here suggest the possibility that the SST anomalies shown in Fig. A1a, if prescribed as the lower-boundary condition for the POS experiment, would remotely force atmospheric anomalies over the midlatitude North Pacific.

Figure A1b presents a map of a one-point regression and correlation of January SST against Z300 at $50^{\circ} \mathrm{N}$, $170^{\circ} \mathrm{W}$ for $1958-2012$, indicating a typical SST anomaly pattern in January when a PNA-like anticyclonic anomaly, as shown in Fig. 2a, is observed as interannual variability. Figure A1b has been constructed in a manner analogous to Fig. A2. Figure A1b suggests that the PNA-like anticyclonic anomaly in Fig. 2a may include a remote influence from the La Niña-like cool SST over the equatorial Pacific but remote influences from other ocean basins are weak.

\section{REFERENCES}

Alexander, M. A., I. Bladé, M. Newman, J. R. Lanzante, N.-C. Lau, and J. D. Scott, 2002: The atmospheric bridge: The influence of ENSO teleconnections on air-sea interaction over the global oceans. J. Climate, 15, 2205-2231, https://doi.org/10.1175/ 1520-0442(2002)015<2205:TABTIO > 2.0.CO;2.

Enomoto, T., A. Kuwano-Yoshida, N. Komori, and W. Ohfuchi, 2008: Description of AFES 2: Improvements for high-resolution and coupled simulations. High Resolution Numerical Modeling of the Atmosphere and Ocean, K. Hamilton and W. Ohfuchi, Eds., Springer, 77-97, https://doi.org/10.1007/978-0-387-49791-4_5.

Feldstein, S. B., 2002: Fundamental mechanisms of the growth and decay of the PNA teleconnection pattern. Quart. J. Roy. Meteor. Soc., 128, 775-796, https://doi.org/10.1256/0035900021643683.

Frankignoul, C., 1985: Sea surface temperature anomalies, planetary waves, and air-sea feedback in the middle latitudes. Rev. Geophys., 23, 357-390, https://doi.org/10.1029/RG023i004p00357.

— N. Sennéchael, Y.-O. Kwon, and M. A. Alexander, 2011: Influence of the meridional shifts of the Kuroshio and the Oyashio Extensions on the atmospheric circulation. J. Climate, 24, 762777, https://doi.org/10.1175/2010JCLI3731.1.

Harada, Y., and Coauthors, 2016: The JRA-55 Reanalysis: Representation of atmospheric circulation and climate variability. J. Meteor. Soc. Japan, 94, 269-302, https://doi.org/10.2151/ jmsj.2016-015.

Hoskins, B. J., I. N. James, and G. H. White, 1983: The shape, propagation and mean-flow interaction of large-scale weather systems. J. Atmos. Sci., 40, 1595-1612, https://doi.org/10.1175/ 1520-0469(1983)040<1595:TSPAMF $>2.0$. CO;2.

Hotta, D., and H. Nakamura, 2011: On the significance of sensible heat supply from the ocean in the maintenance of the mean baroclinicity along storm tracks. J. Climate, 24, 3377-3401, https://doi.org/10.1175/2010JCLI3910.1.

Ishii, M., A. Shouji, S. Sugimoto, and T. Matsumoto, 2005: Objective analyses of sea-surface temperature and marine meteorological variables for the 20th century using ICOADS and the Kobe Collection. Int. J. Climatol., 25, 865-879, https://doi.org/ 10.1002/joc.1169.

Iwasaka, N., and K. Hanawa, 1990: Climatologies of marine meteorological variables and surface fluxes in the North Pacific computed from COADS. Tohoku Geophys. J., 33, 185-240.

Joyce, T. M., Y.-O. Kwon, and L. Yu, 2009: On the relationship between synoptic wintertime atmospheric variability and 
path shifts in the Gulf Stream and the Kuroshio Extension. J. Climate, 22, 3177-3192, https://doi.org/10.1175/ 2008JCLI2690.1.

Kelly, K. A., R. J. Small, R. M. Samelson, B. Qiu, T. M. Joyce, Y.-O. Kwon, and M. F. Cronin, 2010: Western boundary currents and frontal air-sea interaction: Gulf Stream and Kuroshio Extension. J. Climate, 23, 5644-5667, https://doi.org/10.1175/2010JCLI3346.1.

Kida, S., and Coauthors, 2015: Oceanic fronts and jets around Japan: A review. J. Oceanogr., 71, 469-497, https://doi.org/ 10.1007/s10872-015-0283-7.

Kobayashi, S., and Coauthors, 2015: The JRA-55 Reanalysis: General specifications and basic characteristics. J. Meteor. Soc. Japan, 93, 5-48, https://doi.org/10.2151/jmsj.2015-001.

Komori, N., K. Takahashi, K. Komine, T. Motoi, X. Zhang, and G. Sagawa, 2005: Description of sea-ice component of Coupled Ocean-Sea-Ice Model for the Earth Simulator (OIFES). J. Earth Simul., 4, 31-45.

Kosaka, Y., and H. Nakamura, 2006: Structure and dynamics of the summertime Pacific-Japan teleconnection pattern. Quart. J. Roy. Meteor. Soc., 132, 2009-2030, https://doi.org/10.1256/ qj.05.204.

$\longrightarrow$, and —, 2010: Mechanisms of meridional teleconnection observed between a summer monsoon system and a subtropical anticyclone. Part I: The Pacific-Japan pattern. J. Climate, 23, 5085-5108, https://doi.org/10.1175/2010JCLI3413.1.

Kushnir, Y., and N.-C. Lau, 1992: The general circulation model response to a North Pacific SST anomaly: Dependence on time scale and pattern polarity. J. Climate, 5, 271-283, https://doi.org/ 10.1175/1520-0442(1992)005<0271:TGCMRT>2.0.CO;2.

, W. A. Robinson, I. Bladé, N. M. J. Hall, S. Peng, and R. Sutton, 2002: Atmospheric GCM response to extratropical SST anomalies: Synthesis and evaluation. J. Climate, 15, 2233-2256, https://doi.org/10.1175/1520-0442(2002)015<2233: AGRTES $>2.0 . \mathrm{CO} ; 2$.

Kuwano-Yoshida, A., T. Enomoto, and W. Ohfuchi, 2010: An improved PDF cloud scheme for climate simulations. Quart. J. Roy. Meteor. Soc., 136, 1583-1597, https://doi.org/10.1002/ qj.660.

Kwon, Y.-O., and T. M. Joyce, 2013: Northern Hemisphere winter atmospheric transient eddy heat fluxes and the Gulf Stream and Kuroshio-Oyashio Extension variability. J. Climate, 26, 9839-9859, https://doi.org/10.1175/JCLI-D-12-00647.1.

- M. A. Alexander, N. A. Bond, C. Frankignoul, H. Nakamura, B. Qiu, and L. A. Thompson, 2010: Role of the Gulf Stream and Kuroshio-Oyashio systems in large-scale atmosphereocean interaction: A review. J. Climate, 23, 3249-3281, https:// doi.org/10.1175/2010JCLI3343.1.

Lau, N.-C., 1997: Interactions between global SST anomalies and the midlatitude atmospheric circulation. Bull. Amer. Meteor. Soc., 78, 21-33, https://doi.org/10.1175/1520-0477(1997)078<0021: IBGSAA $>2.0 . \mathrm{CO} ; 2$.

__ , and E. O. Holopainen, 1984: Transient eddy forcing of the time-mean flow as identified by geopotential tendencies. J. Atmos. Sci., 41, 313-328, https://doi.org/10.1175/ 1520-0469(1984)041<0313:TEFOTT>2.0.CO;2.

_ atmospheric response to extratropical SST anomalies observed in 1950-79. J. Climate, 3, 965-989, https://doi.org/ 10.1175/1520-0442(1990)003<0965:AGCMSO > 2.0.CO;2.

, and -1991 : Variability of the baroclinic and barotropic transient eddy forcing associated with monthly changes in the midlatitude storm tracks. J. Atmos. Sci., 48, 2589-2613, https:// doi.org/10.1175/1520-0469(1991)048<2589:VOTBAB > 2.0.CO;2.
Liu, Z., Y. Liu, L. Wu, and R. Jacob, 2007: Seasonal and long-term atmospheric responses to reemerging North Pacific Ocean variability: A combined dynamical and statistical assessment. J. Climate, 20, 955-980, https://doi.org/10.1175/JCLI4041.1.

Minobe, S., and A. Maeda, 2005: A $1^{\circ}$ monthly gridded sea-surface temperature dataset compiled from ICOADS from 1850 to 2002 and Northern Hemisphere frontal variability. Int. J. Climatol., 25, 881-894, https://doi.org/10.1002/joc.1170.

Mo, K. C., and R. E. Livezey, 1986: Tropical-extratropical geopotential height teleconnections during the Northern Hemisphere winter. Mon. Wea. Rev., 114, 2488-2515, https://doi.org/ 10.1175/1520-0493(1986)114<2488:TEGHTD>2.0.CO;2.

Nakamura, H., and A. S. Kazmin, 2003: Decadal changes in the North Pacific oceanic frontal zones as revealed in ship and satellite observations. J. Geophys. Res., 108, 3078, https:// doi.org/10.1029/1999JC000085.

_ - M. Tanaka, and J. M. Wallace, 1987: Horizontal structure and energetics of Northern Hemisphere wintertime teleconnection patterns. J. Atmos. Sci., 44, 3377-3391, https://doi.org/ 10.1175/1520-0469(1987)044<3377:HSAEON>2.0.CO;2.

__, G. Lin, and T. Yamagata, 1997: Decadal climate variability in the North Pacific during the recent decades. Bull. Amer. Meteor. Soc., 78, 2215-2225, https://doi.org/10.1175/ 1520-0477(1997)078<2215:DCVITN>2.0.CO;2.

_, T. Sampe, Y. Tanimoto, and A. Shimpo, 2004: Observed associations among storm tracks, jet streams and midlatitude oceanic fronts. Earth's Climate: The Ocean-Atmosphere Interaction, C. Wang, S.-P. Xie, and J. A. Carton, Eds. Amer. Geophys. Union, 329-346, https://doi.org/10.1029/ $147 \mathrm{GM} 18$.

- A. Isobe, S. Minobe, H. Mitsudera, M. Nonaka, and T. Suga, 2015: "Hot spots" in the climate system-New developments in the extratropical ocean-atmosphere interaction research: A short review and an introduction. J. Oceanogr., 71, 463-467, https://doi.org/10.1007/s10872-015-0321-5.

Newman, M., and Coauthors, 2016: The Pacific decadal oscillation, revisited. J. Climate, 29, 4399-4427, https://doi.org/10.1175/ JCLI-D-15-0508.1.

Nishii, K., H. Nakamura, and T. Miyasaka, 2009: Modulations in the planetary wave field induced by upward-propagating Rossby wave packets prior to stratospheric sudden warming events: A case-study. Quart. J. Roy. Meteor. Soc., 135, 39-52, https://doi.org/10.1002/qj.359.

Nonaka, M., H. Nakamura, Y. Tanimoto, T. Kagimoto, and H. Sasaki, 2006: Decadal variability in the Kuroshio-Oyashio Extension simulated in an eddy-resolving OGCM. J. Climate, 19, 1970-1989, https://doi.org/10.1175/JCLI3793.1.

Ohfuchi, W., and Coauthors, 2004: 10-km mesh meso-scale resolving simulations of the global atmosphere on the Earth Simulator-Preliminary outcomes of AFES (AGCM for the Earth Simulator). J. Earth Simul., 1, 8-34.

— H. Sasaki, Y. Masumoto, and H. Nakamura, 2007: "Virtual" atmospheric and oceanic circulations in the Earth Simulator. Bull. Amer. Meteor. Soc., 88, 861-866, https://doi.org/10.1175/ BAMS-88-6-861.

Okajima, S., H. Nakamura, K. Nishii, T. Miyasaka, and A. Kuwano-Yoshida, 2014: Assessing the importance of prominent warm SST anomalies over the midlatitude North Pacific in forcing large-scale atmospheric anomalies during 2011 summer and autumn. J. Climate, 27, 3889-3903, https:// doi.org/10.1175/JCLI-D-13-00140.1.

Onogi, K., and Coauthors, 2007: The JRA-25 Reanalysis. J. Meteor. Soc. Japan, 85, 369-432, https://doi.org/10.2151/jmsj.85.369. 
O'Reilly, C. H., and A. Czaja, 2015: The response of the Pacific storm track and atmospheric circulation to Kuroshio Extension variability. Quart. J. Roy. Meteor. Soc., 141, 52-66, https:// doi.org/10.1002/qj.2334.

Peng, S., and J. S. Whitaker, 1999: Mechanisms determining the atmospheric response to midlatitude SST anomalies. J. Climate, 12, 1393-1408, https://doi.org/10.1175/1520-0442(1999)012<1393: MDTART $>2.0 . \mathrm{CO} ; 2$.

_- and W. A. Robinson, 2001: Relationships between atmospheric internal variability and the responses to an extratropical SST anomaly. J. Climate, 14, 2943-2959, https://doi.org/10.1175/ 1520-0442(2001)014<2943:RBAIVA>2.0.CO;2.

—, L. A. Mysak, J. Derome, H. Ritchie, and B. Dugas, 1995: The differences between early and midwinter atmospheric responses to sea surface temperature anomalies in the northwest Atlantic. J. Climate, 8, 137-157, https://doi.org/10.1175/ 1520-0442(1995)008<0137:TDBEAM > 2.0.CO;2.

_ W. A. Robinson, and M. P. Hoerling, 1997: The modeled atmospheric response to midlatitude SST anomalies and its dependence on background circulation states. J. Climate, 10, 971-987, https://doi.org/10.1175/1520-0442(1997)010<0971: TMARTM $>2.0 . \mathrm{CO} ; 2$.

Reynolds, R. W., T. M. Smith, C. Liu, D. B. Chelton, K. S. Casey, and M. G. Schlax, 2007: Daily high-resolution-blended analyses for sea surface temperature. J. Climate, 20, 5473-5496, https://doi.org/10.1175/2007JCLI1824.1.

Robinson, W. A., 2000: Review of WETS-The workshop on extra-tropical SST anomalies. Bull. Amer. Meteor. Soc., 81, 567-577, https://doi.org/10.1175/1520-0477(2000)081<0567: ROWTWO $>2.3 . \mathrm{CO} ; 2$.

Schneider, N., A. J. Miller, and D. W. Pierce, 2002: Anatomy of North Pacific decadal variability. J. Climate, $\mathbf{1 5}$, 586-605, https://doi.org/10.1175/1520-0442(2002)015<0586: AONPDV $>2.0 . C O ; 2$.

Seager, R., Y. Kushnir, N. H. Naik, M. A. Cane, and J. Miller, 2001: Wind-driven shifts in the latitude of the Kuroshio-Oyashio Extension and generation of SST anomalies on decadal timescales. J. Climate, 14, 4249-4265, https://doi.org/10.1175/ 1520-0442(2001)014<4249:WDSITL $>2.0 . \mathrm{CO} ; 2$.

Simmons, A. J., J. M. Wallace, and G. W. Branstator, 1983: Barotropic wave propagation and instability, and atmospheric teleconnection patterns. J. Atmos. Sci., 40,1363-1392, https:// doi.org/10.1175/1520-0469(1983)040<1363:BWPAIA >2.0.CO;2.

Smirnov, D., M. Newman, and M. A. Alexander, 2014: Investigating the role of ocean-atmosphere coupling in the North Pacific Ocean. J. Climate, 27, 592-606, https://doi.org/ 10.1175/JCLI-D-13-00123.1.

,,-- Y.-O. Kwon, and C. Frankignoul, 2015: Investigating the local atmospheric response to a realistic shift in the Oyashio sea surface temperature front. J. Climate, 28, 1126-1147, https://doi.org/10.1175/JCLI-D-14-00285.1.

Smith, T. M., R. W. Reynolds, T. C. Peterson, and J. Lawrimore, 2008: Improvements to NOAA's historical merged landocean surface temperature analysis (1880-2006). J. Climate, 21, 2283-2296, https://doi.org/10.1175/2007JCLI2100.1.
Sutton, R., and P.-P. Mathieu, 2002: Response of the atmosphereocean mixed-layer system to anomalous ocean heat-flux convergence. Quart. J. Roy. Meteor. Soc., 128, 1259-1275, https:// doi.org/10.1256/003590002320373283.

Taguchi, B., S.-P. Xie, N. Schneider, M. Nonaka, H. Sasaki, and Y. Sasai, 2007: Decadal variability of the Kuroshio Extension: Observations and an eddy-resolving model hindcast. J. Climate, 20, 2357-2377, https://doi.org/10.1175/JCLI4142.1.

, H. Nakamura, M. Nonaka, and S.-P. Xie, 2009: Influences of the Kuroshio/Oyashio Extensions on air-sea heat exchanges and storm-track activity as revealed in regional atmospheric model simulations for the 2003/04 cold season. J. Climate, 22, 6536-6560, https://doi.org/10.1175/2009JCLI2910.1.

$-,-\ldots, \ldots$, N. Komori, A. Kuwano-Yoshida, K. Takaya, and A. Goto, 2012: Seasonal evolutions of atmospheric response to decadal SST anomalies in the North Pacific subarctic frontal zone: Observations and a coupled model simulation. J. Climate, 25, 111-139, https://doi.org/10.1175/ JCLI-D-11-00046.1.

Tanaka, S., K. Nishii, and H. Nakamura, 2016: Vertical structure and energetics of the western Pacific teleconnection pattern. J. Climate, 29, 6597-6616, https://doi.org/10.1175/ JCLI-D-15-0549.1.

Tanimoto, Y., N. Iwasaka, and K. Hanawa, 1997: Relationships between sea surface temperature, the atmospheric circulation and air-sea fluxes on multiple time scales. J. Meteor. Soc. Japan, 75, 831-849, https://doi.org/10.2151/jmsj1965.75.4_831.

,- H. Nakamura, T. Kagimoto, and S. Yamane, 2003: An active role of extratropical sea surface temperature anomalies in determining anomalous turbulent heat flux. J. Geophys. Res., 108, 3304, https://doi.org/10.1029/2002JC001750.

Wallace, J. M., and D. S. Gutzler, 1981: Teleconnections in the geopotential height field during the Northern Hemisphere winter. Mon. Wea. Rev., 109, 784-812, https://doi.org/10.1175/ 1520-0493(1981)109<0784:TITGHF>2.0.CO;2.

Worley, S. J., S. D. Woodruff, R. W. Reynolds, S. J. Lubker, and N. Lott, 2005: ICOADS release 2.1 data and products. Int. J. Climatol., 25, 823-842, https://doi.org/10.1002/joc.1166.

Yasuda, I., 2003: Hydrographic structure and variability in the Kuroshio-Oyashio transition area. J. Oceanogr., 59, 389-402, https://doi.org/10.1023/A:1025580313836.

Zheng, X., H. Nakamura, and J. A. Renwick, 2000: Potential predictability of seasonal means based on monthly time series of meteorological variables. J. Climate, 13, 25912604, https://doi.org/10.1175/1520-0442(2000)013<2591: PPOSMB $>2.0 . \mathrm{CO} ; 2$.

Zhou, G., M. Latif, R. J. Greatbatch, and W. Park, 2015: Atmospheric response to the North Pacific enabled by daily sea surface temperature variability. Geophys. Res. Lett., 42, 77327739, https://doi.org/10.1002/2015GL065356.

,,--- , and ——, 2017: State dependence of atmospheric response to extratropical North Pacific SST anomalies. J. Climate, 30, 509-525, https://doi.org/10.1175/ JCLI-D-15-0672.1. 